\title{
Travel to high altitude with pre-existing lung disease
}

\author{
A.M. Luks* and E.R. Swenson\#
}

ABSTRACT: The pathophysiology of high-altitude illnesses has been well studied in normal individuals, but little is known about the risks of high-altitude travel in patients with pre-existing lung disease. Although it would seem self-evident that any patient with lung disease might not do well at high altitude, the type and severity of disease will determine the likelihood of difficulty in a high-altitude environment. The present review examines whether these individuals are at risk of developing one of the main forms of acute or chronic high-altitude illness and whether the underlying lung disease itself will get worse at high elevations. Several groups of pulmonary disorders are considered, including obstructive, restrictive, vascular, control of ventilation, pleural and neuromuscular diseases. Attempts will be made to classify the risks faced by each of these groups at high altitude and to provide recommendations regarding evaluation prior to high-altitude travel, advice for or against taking such excursions, and effective prophylactic measures.

KEYWORDS: Acute mountain sickness, high altitude, high-altitude cerebral oedema, high-altitude pulmonary oedema, hypoxia, lung disease

$\mathbf{M}$ any people travel to high altitude each year. For example, roughly 9,000 people attempt to climb Mount Rainier (WA, USA; elevation 4,392 m) annually [1] and nearly 1.6 million visit a Colorado ski resort whose base elevation is $2,476 \mathrm{~m}$ [2]. People who ascend to such elevations are at risk for a variety of problems, including acute mountain sickness (AMS), high-altitude cerebral oedema (HACE) and high-altitude pulmonary oedema (HAPE). The incidence of these altitude illnesses is well defined for normal individuals, but little information is available regarding the risk of developing altitude illness in patients with pre-existing lung disease. The same is true for the question of whether the underlying lung disease itself will get worse at high altitude. While the majority of people going to high altitudes are healthy individuals, it would be a mistake to assume that high-altitude travel is limited to such groups. Even if those with lung disease do not engage in vigorous activities such as skiing or climbing, exposure to highaltitude environments through work, leisure activities, commercial air flight or car travel over high mountain passes may result in predictable consequences.
The present review examines the problems posed by high altitude for individuals with pulmonary disease. Specifically, the risk of developing acute and chronic forms of altitude illness is addressed, along with whether the underlying disease will worsen with ascent to high elevations. The likely risks at high altitude for those with obstructive, restrictive, vascular, control of ventilation, pleural and neuromuscular disorders is discussed and recommendations for or against travel to high altitude, pre-travel evaluation and effective prophylactic measures are offered.

Owing to the limited literature on these issues, some caution must be applied in considering these risks and making recommendations. As a result, the conclusions of the present review rest on an understanding of the specific disease pathophysiology and how that pathophysiology might interact with the high-altitude environment, complemented as much as possible by studies with small patient numbers that focus on narrow end-points or on case reports with limited generalisability. Nevertheless, reasonable tentative conclusions can be drawn to guide evaluation of such patients before ascent to high elevation and their management during the high-altitude sojourn.

\section{AFFILIATIONS}

*Division of Pulmonary and Critical Care Medicine, University of Washington, and

\#Division of Pulmonary and Critical Care Medicine, Seattle Veterans Affairs Medical Center, Seattle, WA, USA.

\section{CORRESPONDENCE}

A.M. Luks

Division of Pulmonary and Critical Care Medicine

Puget Sound Veterans Affairs Health Care System

1660 South Columbian Way S111PULM

Seattle

WA 98108

USA

Fax: 12067642659

E-mail: aluks@u.washington.edu

Received:

April 172006

Accepted after revision:

October 012006

STATEMENT OF INTEREST

None declared.

European Respiratory Journal

Print ISSN 0903-1936

Online ISSN 1399-3003 


\section{ENVIRONMENTAL CHANGES AT HIGH ALTITUDE THAT MAY AFFECT PULMONARY FUNCTION}

Before considering how patients with pulmonary disease are affected at high altitude, it is useful to review the environmental changes at high elevations that may affect pulmonary function.

The most significant change at high altitude is the nonlinear decrease in barometric pressure with increasing elevation. This change is more pronounced at higher latitudes and during the winter [3] and leads to lower inspired oxygen partial pressure, alveolar oxygen partial pressure $\left(P \mathrm{~A}, \mathrm{O}_{2}\right)$ and arterial oxygen tension $\left(\mathrm{Pa}_{\mathrm{a}} \mathrm{O}_{2}\right)$ values. Air density and ambient temperature also decrease, with the latter falling at a rate of $1{ }^{\circ} \mathrm{C}$ for every $150-\mathrm{m}$ gain in elevation [4]. With lower temperatures, the absolute humidity is reduced relative to sea-level values; this in turn leads to greater insensible water losses through the respiratory tract, particularly when minute ventilation is increased during exercise [4].

Air quality also changes with increasing altitude. As discussed further below, the burden of house-dust mites, important allergens in asthmatic patients, decreases with increasing altitude [5,6]. Other aspects of air quality, however, might actually worsen with increasing elevation. For example, heavyduty diesel truck on-road emissions increase with rising altitude [7]. In areas such as the Himalayas, wood and yakdung stoves are common heat sources and so the air quality in villages is often poor in the early evenings and mornings. Increasing elevation also leads to more intense solar radiation, which produces more accelerated photochemistry and greater smog potential. Finally, many mountain areas have extensive valley systems in which frequent temperature inversions trap pollutants.

\section{THE NORMAL PULMONARY RESPONSE TO HIGH ALTITUDE}

In order to understand the problems lung disease patients may experience at high altitude, it is useful to review the normal physiological responses to hypobaric hypoxia. While the lungs play the primary role in the early and late responses to high altitude, other organ systems including the heart, kidneys and haematological system undergo important adaptations. These changes, some of which occur immediately and others over days to weeks, are discussed below with an emphasis on those involving the respiratory system.

\section{Ventilation}

With the fall in barometric pressure and subsequent decreased $\mathrm{Pa}_{1} \mathrm{O}_{2}$, there is a compensatory increase in ventilation, known as the hypoxic ventilatory response (HVR). BASU et al. [8], for example, showed that resting ventilation in healthy males increased from $7.03 \pm 0.3 \mathrm{~L} \cdot \mathrm{min}^{-1}$ at sea level to $11.8 \pm 0.5 \mathrm{~L} \cdot \mathrm{min}^{-1}$ on the first day at $3,110 \mathrm{~m}$. Resting ventilation continues to rise with extended time at altitude. If the increase in ventilation does not occur, the $P A, \mathrm{O}_{2}$ and $\mathrm{Pa}_{1} \mathrm{O}_{2}$ will be lower at any given barometric pressure than when these ventilatory changes occur as expected $[9,10]$. The HVR carries a cost, however, as respiratory muscle oxygen consumption rises with increasing altitude and ventilatory demands require a greater fraction of a person's ventilatory reserve or maximal voluntary ventilation (MVV). For instance, if a patient's MVV is only $25 \mathrm{~L} \cdot \mathrm{min}^{-1}$, then the obligatory $4-5 \mathrm{~L} \cdot \mathrm{min}^{-1}$ increase in ventilation at $3,110 \mathrm{~m}$ will have the effect of requiring the patient to breathe at almost $50 \%$ of MVV in contrast to perhaps $10 \%$ of MVV for a healthy person. The increased work of breathing also demands greater blood flow for the respiratory muscles and, as a result, may "steal" cardiac output from other working muscles, thereby limiting exercise capacity $[11,12]$.

\section{Gas exchange and oxygen delivery}

Multiple factors affect lung gas exchange and arterial oxygenation at high altitude. The low $\mathrm{PA}_{\mathrm{A}} \mathrm{O}_{2}$ limits the alveolar-arterial driving gradient for oxygen uptake and, in combination with a lower mixed venous oxygen tension, also delays alveolar-capillary equilibration [13]. These issues are of greater concern during exercise when the smaller pressure differential across the alveolar-capillary barrier, in conjunction with the increased cardiac output, shortened capillary transit time and greater venous oxygen desaturation, create an effective diffusion limitation for oxygen that leads to further arterial desaturation $[9,10,14]$. Compounding these effects is increased extravascular lung water at high altitude, for which there is indirect evidence, which may impair gas exchange by creating more ventilation-perfusion inequality [15-17].

The fall in $\mathrm{Pa}, \mathrm{O}_{2}$ decreases blood oxygen content, but the effect on oxygen delivery is partly mitigated by a rise in cardiac output, haemoconcentration by a mild diuretic effect of hypoxia and, eventually, by hypoxia-mediated erythropoietin secretion and increased red blood cell production. Finally, for any given $\mathrm{Pa}_{2} \mathrm{O}_{2}$, arterial saturation will initially be higher at high altitude because the acute respiratory alkalosis arising from hyperventilation causes a leftward shift in the haemoglobin-oxygen dissociation curve. This shift, which improves oxygen uptake in the lungs more than it impairs off-loading in the tissues, diminishes over time as the dissociation curve shifts to the right in response to increased 2,3-diphoshoglycerate production and renal compensation for the respiratory alkalosis. These changes occur rapidly (within 1-2 days) following ascent to elevations $<5,000 \mathrm{~m}$, and, as a result, the overall position of the dissociation curve is essentially unchanged from its baseline position at sea level. The alkalosis-induced changes in the position of the haemoglobin-oxygen dissociation curve are likely to be irrelevant until one ascends to elevations $>5,000 \mathrm{~m}$ where very high levels of ventilation provoke a marked respiratory alkalosis which will, in fact, shift the position of the dissociation curve. WEST et al. [13], for example, used venous blood gas samples to calculate an estimated arterial $\mathrm{pH}$ of 7.7 on the summit of Mount Everest, a result which suggests that extreme hyperventilation may be necessary at extreme altitudes in order to facilitate uptake of adequate amounts of oxygen.

\section{Pulmonary vascular system}

At high altitude, alveolar hypoxia triggers hypoxic pulmonary vasoconstriction (HPV) and a subsequent rise in pulmonary arterial pressure $(P$ pa $)[18,19]$; left atrial pressures remain normal and the rise in Ppa persists over time [20-23]. BERGER et al. [22], for example, exposed healthy individuals to normobaric hypoxia and found that the systolic $P$ pa rose from $22 \pm 3 \mathrm{mmHg}$ at an inspired oxygen fraction $\left(\mathrm{FI}_{1} \mathrm{O}_{2}\right)$ of 0.21 to $33 \pm 6 \mathrm{mmHg}$ after $4 \mathrm{~h}$ of breathing an $\mathrm{FI}_{1} \mathrm{O}_{-2}$ of 0.12 . There is a 
large variability of HPV in normal healthy individuals, spanning almost a ten-fold range in $P$ pa changes with acute hypoxia [21]. Despite the fact that some individuals develop marked pulmonary hypertension, surprisingly, no cases of acute right heart failure have been described during mountaineering or scientific expeditions to high altitude [24]. Those individuals with very large HPV are, however, at risk of HAPE and possibly subacute and chronic mountain sickness, illnesses which are discussed in the following section on specific highaltitude illnesses.

\section{Pulmonary mechanics}

Various changes in pulmonary mechanics have been described at high altitude. Studies in simulated and actual high-altitude environments consistently show a fall in vital capacity $[8,25-$ 28]. This change occurs within the first day and persists over time at high altitude $[27,28]$. Various mechanisms have been proposed to explain this change including pulmonary vascular engorgement, mild interstitial oedema [28], increased abdominal distension [26] and decreased respiratory muscle strength [29]. In contrast, total lung capacity (TLC) is increased at altitude [25, 30], suggesting that residual volume is increased as well. Conflicting data have been reported regarding changes in the forced expiratory volume in one second (FEV1) as various studies have reported an increase [31], a decrease [8] or no change $[27,28]$. Despite inconsistent data on changes in FEV1, there is clear evidence that peak expiratory flow rates (PEFR) are increased [8, 27, 30, 32] and airways resistance is reduced [30, 31], changes that most likely stem from the decreased air density at high altitude.

Conflicting data exist regarding changes in static lung compliance. KRONENBERG et al. [20] reported decreased compliance in four healthy individuals over $72 \mathrm{~h}$ at 3,800 m, but subsequent studies have shown that compliance is increased at high altitude [30, 33]. Similar variable results have been reported regarding respiratory muscle strength. Dевовск et al. [29] reported decreased maximum inspiratory and expiratory pressures at a simulated altitude of $4,267 \mathrm{~m}$, while FORTE et al. [34] showed no change in these variables at 4,300 $\mathrm{m}$. The reasons for all of these conflicting results may relate to various methodological differences between the studies such as the altitude reached, the speed of ascent, and other elements of the research programme which might have altered the observed results. Unfortunately, with all of these disparities between the various studies, it is difficult to determine which are the more valid outcomes.

\section{HIGH-ALTITUDE ILLNESS}

Before discussing the specific forms of lung disease and how these patients will fare at high altitude, it is useful to briefly describe the main forms of altitude-related disease: AMS; HACE; HAPE; subacute mountain sickness; and chronic mountain sickness. The information discussed below is summarised in table 1. For a detailed discussion of these issues, the reader is referred to several excellent reviews on these topics [35-39].

\section{Acute mountain sickness}

AMS is a syndrome that affects $22-53 \%$ of travellers to altitudes between 1,850 and 4,240 m, with higher incidences being described at the higher elevations [40,41]. Marked by the presence of headache plus one or more other symptoms including fatigue, loss of appetite, nausea, vomiting, dizziness and poor sleep, it is typically seen above $2,500 \mathrm{~m}$ and begins within $6-10 \mathrm{~h}$ of ascent. The primary risk factors for developing AMS include the altitude reached and the rate of ascent. There are no specific physical examination findings or laboratory studies and the diagnosis is made on the basis of presenting symptoms. Diagnosis and severity of illness can also be assessed using the Lake Louise AMS Scoring system [42]. The disorder is best prevented by undertaking a slow ascent to high elevation. Acetazolamide and dexamethasone have both also been proven to be effective prophylactic options [43-45]. Adequate treatment requires cessation of ascent, symptomatic treatment with non-narcotic pain relievers and acetazolamide [46]. If symptoms do not resolve with appropriate treatment, descent is required. Affected individuals should not ascend further until symptoms have abated.

\section{High-altitude cerebral oedema}

HACE is a very rare but life-threatening condition defined by the presence of ataxia, altered mental status or both in a patient with preceding symptoms of either AMS or HAPE [35]. It derives from the same pathophysiology as AMS, but represents a more severe progression of these processes. Cases are typically seen above $4,000 \mathrm{~m}$ and, as with AMS, the primary risk factor is an overly rapid ascent to high elevations. Ataxia and signs of global encephalopathy are the primary physical exam findings. Preventive measures are the same as for AMS. Treatment requires immediate descent to lower elevations or, if this is not feasible, supplemental oxygen or a portable hyperbaric chamber. Affected patients should also be treated with dexamethasone. If not recognised and treated promptly, HACE can lead to brain herniation and death.

\section{High-altitude pulmonary oedema}

HAPE is a noncardiogenic pulmonary oedema that affects $0.2-$ $15 \%$ of high-altitude travellers, depending on the altitude reached and the rate of ascent $[47,48]$. Generally seen above 3,000 m, it occurs within 2-5 days of ascent and can develop without preceding symptoms of AMS or HACE. Risk factors include the altitude reached, the rate of ascent, overexertion and cold-air exposure. Individual susceptibility also plays a role, as HAPE-susceptible individuals have been shown to have exaggerated pulmonary vascular responses to hypoxia and exercise in normoxia [23,49-51]. Initial symptoms include decreased exercise performance and a dry cough. With worsening disease, patients develop dyspnoea with minimal activity and a cough productive of pink frothy sputum. Physical examination often reveals resting tachycardia, cyanosis, low-grade fever, and crackles on auscultation. Disease prevention entails undertaking a slow ascent to high altitude and avoiding overexertion. Patients with a history of HAPE should be considered for prophylaxis with nifedipine and/or salmeterol, both of which have been proven effective in randomised, placebo-controlled studies [52, 53]. Treatment requires descent, or, if this is not feasible, supplemental oxygen or a portable hyperbaric chamber. Treatment with nifedipine should also be initiated. Death can occur if the disease is not recognised and treated promptly. 


\section{TABLE 1 Summary of the major high-altitude illnesses}

\begin{tabular}{|c|c|c|c|}
\hline AMS & $\begin{array}{l}\text { Headache plus one or more of the } \\
\text { following: lightheadedness; nausea; } \\
\text { vomiting; lethargy; poor sleep }\end{array}$ & $\begin{array}{l}\text { Slow ascent; avoid overexertion; acetazolamide } \\
125 \mathrm{mg} \text { or } 250 \mathrm{mg} \text { b.i.d. or dexamethasone } \\
2 \mathrm{mg} \text { q.i.d. }\end{array}$ & $\begin{array}{l}\text { Stop ascending; non-narcotic pain relievers for } \\
\text { headache; antiemetics; acetazolamide } \\
250 \mathrm{mg} \text { b.i.d. }\end{array}$ \\
\hline HACE & $\begin{array}{l}\text { Pre-existing symptoms of AMS or HAPE; } \\
\text { ataxia; altered mental status; coma }\end{array}$ & $\begin{array}{l}\text { Slow ascent; avoid overexertion; acetazolamide } \\
125 \mathrm{mg} \text { or } 250 \mathrm{mg} \text { b.i.d. or dexamethasone } \\
2 \mathrm{mg} \text { q.i.d. }\end{array}$ & $\begin{array}{l}\text { Descend until symptoms resolve; supplemental } \\
\text { oxygen; portable hyperbaric chamber; } \\
\text { dexamethasone } 1 \times 8 \mathrm{mg} \text { then } 4 \mathrm{mg} \text { q.i.d. }\end{array}$ \\
\hline $\begin{array}{l}\text { Subacute } \\
\text { Mountain } \\
\text { Sickness }\end{array}$ & $\begin{array}{l}\text { Dyspnoea; exercise angina; cough; } \\
\text { ascites; peripheral oedema; } \\
\text { cardiomegaly; polycythaemia }\end{array}$ & No documented strategies for prevention & Diuretic therapy; descent to lower elevation \\
\hline $\begin{array}{l}\text { Polycythaemic } \\
\text { form }\end{array}$ & $\begin{array}{l}\text { Headache; lethargy; confusion; mucosal } \\
\text { congestion; cyanosis; clubbing }\end{array}$ & No documented strategies for prevention & $\begin{array}{l}\text { Descent to lower elevation; alternatives to } \\
\text { descent include periodic phlebotomy and } \\
\text { respiratory stimulants }\end{array}$ \\
\hline $\begin{array}{l}\text { Isolated right } \\
\text { heart failure }\end{array}$ & $\begin{array}{l}\text { Headache; dyspnoea; cough; oedema; } \\
\text { cyanosis; tachycardia; hepatomegaly }\end{array}$ & & Descent to lower elevation \\
\hline
\end{tabular}

\section{Subacute mountain sickness and chronic mountain sickness}

While AMS, HACE and HAPE are only seen with acute exposure (2-5 days) to high altitude, two other forms of altitude illness are seen with longer durations of exposure: subacute mountain sickness and chronic mountain sickness. Subacute mountain sickness was originally described by ANAND et al. [54], who reported 21 cases of right heart failure in Indian soldiers posted to elevations between 5,800 and $6,700 \mathrm{~m}$ for an average of 10 weeks. Affected individuals, who are likely to have an exaggerated hypoxic pulmonary vasoconstrictor response [55], complain of dyspnoea, cough and exercise-induced angina, and demonstrate evidence of ascites, peripheral oedema, polycythaemia, cardiomegaly and pericardial effusion. Treatment involves evacuation to lower elevations, which leads to rapid resolution of the disorder. Subacute altitude illness is generally not seen in populations living at moderate altitudes between 3,300 and $5,000 \mathrm{~m}$ in places such as Leadville (CO, USA) and the Andes Mountains, where the more modest rise in $P$ pa can generally be tolerated for long periods of time.

At these more moderate elevations, however, long-term residents ( $>1 \mathrm{yr}$ ) can develop one of two forms of chronic altitude illness. Monge and WhitTembury [56] described a syndrome marked by the triad of polycythaemia, hypoxaemia and impaired mental function in which affected individuals complain of headache, fatigue, impaired concentration, irritability and impaired exercise tolerance, and physical examination demonstrates clubbing, congested mucosal surfaces and cyanosis. Treatment involves relocation to lower elevations or, in cases where relocation is not feasible, periodic phlebotomy
[57], isovolaemic haemodilution [58, 59] and long-term use of respiratory stimulants such as acetazolamide [60] or medroxyprogesterone [61]. Right heart failure was not described in the report by MONGE and WhITTEMBURy [56], but has subsequently been described in advanced stages of the disease in populations outside the Andes [62]. Additional reports from areas outside the Andes $[63,64]$ have also described an alternative form of chronic altitude illness marked by the presence of pulmonary hypertension and right heart failure without polycythaemia. Affected individuals complain of headache, cough, dyspnoea and irritability and show evidence of cyanosis, tachycardia, hepatomegaly and peripheral oedema. Treatment involves descent to lower elevation, but symptoms recur with re-ascent to high altitude.

Having reviewed the main forms of high-altitude illness and discussed other aspects of high-altitude physiology, the different forms of lung disease and how patients with these diseases may fare at high altitude will now be discussed.

\section{OBSTRUCTIVE LUNG DISEASES}

\section{Chronic obstructive pulmonary disease}

Given the high prevalence of chronic obstructive pulmonary disease (COPD) in the general population, it is likely that many patients are exposed to high altitude by either long-term residence or in the short term via car trips through mountainous areas, vacations to high-altitude locations or commercial air flight. The many physiological problems of COPD, including gas-exchange inefficiency, increased ventilatory requirements, reduced muscle strength and mild-moderate pulmonary hypertension, all of which might be affected by 
high altitude, require that COPD patients be assessed prior to any significant time in a high-altitude environment.

\section{COPD and long-term high-altitude residence}

Multiple studies have demonstrated that long-term residence at altitude is associated with increased mortality and a higher incidence of cor pulmonale in COPD patients [65-68]. For example, CoTE et al. [65] reported a $1 / 10^{5}$ increase in mortality for every increase of $95 \mathrm{~m}$ in residential altitude and MOORE et al. [66] reported that such patients died at a younger age and after a shorter duration of illness when compared to sea-level patients. The only report to the contrary is that of Coultas et al. [69] who found that mortality rates among COPD patients in New Mexico did not increase with altitude. They hypothesised that the discrepancy might be due to differences in occupational exposures and the fact that they examined data from a later period when supplemental oxygen use was more prevalent. Despite these results from Coultas et al. [69], there is at least enough evidence to suggest that long-term residence at high altitude is a potential problem for COPD patients and to consider recommending that they avoid permanent residence in such locations.

\section{Gas exchange}

With respect to more short-term exposures, the key question is whether COPD patients can maintain an adequate $\mathrm{Pa}_{1} \mathrm{O}_{2}$ at altitude or whether they should travel to such areas with supplemental oxygen. Only one study has directly examined this question in a mountainous area. GRAHAM and HOUSTON [70] took eight patients with COPD and an average FEV1 of 1.27 $\mathrm{L}$ to $1,920 \mathrm{~m}$ and found that the $\mathrm{Pa}_{1} \mathrm{O}_{2}$ fell from a sea-level average of $8.8 \mathrm{kPa}(66 \mathrm{mmHg})$ to $7.2 \mathrm{kPa}(54 \mathrm{mmHg})$ within $3 \mathrm{~h}$ of arrival at altitude. In the absence of other field studies, there is extensive literature regarding the use of supplemental oxygen on COPD patients with hypoxaemia on commercial aircraft flights. Exposure to hypobaric hypoxia equivalent to $2,348 \mathrm{~m}$ in elevation causes $\mathrm{Pa}_{\mathrm{a}_{2}}$ to fall below $6.7 \mathrm{kPa}$ $(50 \mathrm{mmHg})$ in COPD patients [71-73]. With mild degrees of exercise under similar conditions, $\mathrm{Pa}_{\mathrm{a}} \mathrm{O}_{2}$ will fall even further [72, 74]. SECCOMBE et al. [74], for example, performed a 50-m walk test on COPD patients breathing inspired air with an $\mathrm{FI}, \mathrm{O}_{2}$ of 0.15 and found that $\mathrm{Pa}, \mathrm{O}_{2}$ fell from $6.09 \pm 0.51 \mathrm{kPa}(45.8 \pm$ $3.8 \mathrm{mmHg})$ at rest to $5.28 \pm 0.40 \mathrm{kPa}(39.7 \pm 3.0 \mathrm{mmHg})$. The fall in $\mathrm{Pa}_{1} \mathrm{O}_{2}$ at rest is reversible with supplemental oxygen, as demonstrated by BERG et al. [73], who found that $4 \mathrm{~L} \cdot \mathrm{min}^{-1}$ delivered by nasal cannula raised $\mathrm{Pa}_{2} \mathrm{O}_{2}$ by an average of $5.24 \pm 1.97 \mathrm{kPa}(34.9 \pm 14.8 \mathrm{mmHg})$. It should be noted that no studies have examined patients above an equivalent altitude of $3,048 \mathrm{~m}$ and, as a result, no conclusions can be drawn about outcomes and the effectiveness of oxygen supplementation above this altitude.

The $6.7-\mathrm{kPa}(50-\mathrm{mmHg})$ level noted above is significant because this is the threshold above which $\mathrm{Pa}_{2} \mathrm{O}_{2}$ should be maintained during commercial flight according to guidelines set by the American Thoracic Society [75]. An alternative set of guidelines from the Aerospace Medical Association sets this threshold at $7.3 \mathrm{kPa}(55 \mathrm{mmHg})$ [76]. These are arbitrarily defined values and neither set of guidelines provides the rationale for why these thresholds were chosen. However, they seem reasonable as $\mathrm{Pa}_{1} \mathrm{O}_{2}$ values in this range ensure arterial oxygen saturations above $85 \%$ and lie above the steep portion of the haemoglobin-oxygen dissociation curve. In the absence of any data suggesting alternative thresholds, they are the standard for deciding which patients require supplemental oxygen in flight or, by logical extension, with travel to high altitude. The question then arises as to whether it is possible to predict in which COPD patients the $\mathrm{Pa}_{\mathrm{a}} \mathrm{O}_{2}$ will fall below these thresholds. GONG JR et al. [77] reported that sea-level $\mathrm{Pa}_{\mathrm{a}} \mathrm{O}_{2}$ values of 9.0 and $9.6 \mathrm{kPa}$ (68 and $72 \mathrm{mmHg}$ ) successfully classified $>90 \%$ of COPD patients with a $\mathrm{Pa}_{1} \mathrm{O}_{2}>7.3 \mathrm{kPa}$ $(55 \mathrm{mmHg})$ at $1,524 \mathrm{~m}$ and $>7.3 \mathrm{kPa}(55 \mathrm{mmHg})$ at 2,348 $\mathrm{m}$, respectively. The Aerospace Medical Association guidelines also affirm that a sea-level $\mathrm{Pa}_{1} \mathrm{O}_{2}$ of $9.7 \mathrm{kPa}(73 \mathrm{mmHg})$ is adequate for ensuring a safe $\mathrm{Pa}_{\mathrm{O}_{2}}$ during exposure to conditions equivalent to $2,348 \mathrm{~m}$ in elevation, the maximum level typically experienced on commercial aircraft [78]. CHRISTENSEN et al. [72], however, question these results. In their study of $15 \mathrm{COPD}$ patients with baseline $\mathrm{Pa}_{1} \mathrm{O}_{2}>9.7 \mathrm{kPa}$ (73 $\mathrm{mmHg}$ ), they found that the resting $\mathrm{Pa}_{1} \mathrm{O}_{2}$ fell to $<6.7 \mathrm{kPa}$ $(50 \mathrm{mmHg}$ ) in $33 \%$ of patients at $2,348 \mathrm{~m}$ and $66 \%$ of patients at $3,048 \mathrm{~m}$. Alternative methods of better predicting the $\mathrm{Pa}, \mathrm{O}_{2}$ at altitude have been proposed. Several studies have shown that combining sea-level FEV1 values with the sea-level $\mathrm{Pa}_{1} \mathrm{O}_{2}$ improved prediction of $\mathrm{Pa}_{2} \mathrm{O}_{2}$ at altitude [71, 79]. CHRISTENSEN et al. [72] found that all subjects in their study whose pre-flight maximum oxygen uptake exceeded $12 \mathrm{~mL} \cdot \mathrm{kg}^{-1} \cdot \mathrm{min}^{-1}$ maintained a $\mathrm{Pa}_{1} \mathrm{O}_{2}>6.7 \mathrm{kPa}(50 \mathrm{mmHg})$ at $2,348 \mathrm{~m}$, but no further studies have been carried out to validate this finding.

In assessing the decrease in $\mathrm{Pa}_{1} \mathrm{O}_{2}$ at altitude, it is worth considering whether the changes observed in the studies cited above are of any clinical significance. It is noteworthy that none of the studies cited above reported adverse events, even in cases where the $\mathrm{Pa}_{2} \mathrm{O}_{2}$ fell to $<6.7 \mathrm{kPa}$ (50 mmHg). GONG JR et al. [77] reported the presence of new asymptomatic arrhythmias during the hypoxia-altitude simulation test in two of their 22 subjects. Of these, 11 subjects also experienced mild symptoms including dyspnoea, headache and dizziness, which did not correlate with the level of hypoxaemia. The only symptoms reported in other studies were dyspnoea $[80,81]$ and mild fatigue [70], but even these symptoms were absent in several of the studies [72, 74, 82]. The lack of symptoms in many of these studies suggests that patients who are chronically hypoxic at sea level might tolerate falls in $\mathrm{Pa}_{1} \mathrm{O}_{2}$ to $<6.7 \mathrm{kPa}(50 \mathrm{mmHg}$ ) because they are already "acclimatised" to some extent. Before one concludes, however, that all COPD patients will tolerate these falls in their $\mathrm{Pa}_{\mathrm{a}} \mathrm{O}_{2}$ at altitude without adverse consequences, it is important to note that these studies examined small numbers of individuals, and included patients with an average FEV1 of 1-1.5 L and without carbon dioxide retention. No conclusions can be drawn about patients with more severe disease or evidence of hypercapnia. In addition, the exposure duration in these studies was shorter than what an individual would experience during a prolonged sojourn to high altitude.

\section{Airflow obstruction}

Independent of arterial oxygenation, altitude may also alter the degree of airflow obstruction. Theoretically, the lower air density at altitude should improve airflow dynamics. FINKELSTEIN et al. [83] exposed 10 patients with COPD and a 
mean FEV1/forced vital capacity (FVC) ratio of $51 \%$ to the equivalent of 5,488 $\mathrm{m}$ in a hypobaric chamber and found that the vital capacity fell from a mean of $2.97 \mathrm{~L}$ to $2.72 \mathrm{~L}$ while the FEV1/FVC ratio improved, increasing from 51 to $57 \%$. They also noted improvement in MVV from 60 to $73 \mathrm{~L} \cdot \mathrm{min}^{-1}$ and improvements in the maximal expiratory flow rates from 1.45 to $1.55 \mathrm{~L} \cdot \mathrm{s}^{-1}$. In their study of 18 COPD patients with a mean baseline FEV1 of $31 \%$ predicted, DILLARD et al. [84] found no statistically significant differences in vital capacity, FEV1, MVV or PEFR at a simulated altitude of 2,348 m. Conversely, several studies suggest that hypoxaemia may worsen bronchoconstriction in some COPD patients [85, 86]. A weakness in all of these studies was the failure to replicate the lower ambient temperature of higher altitudes. KOSKELA et al. [87], for example, exposed $20 \mathrm{COPD}$ patients to $-17^{\circ} \mathrm{C}$ and found that FEV1 fell by an average of $9.4 \pm 1.4 \%$. When the same subjects were asked to hyperventilate cold air while sitting in a warm room, the FEV1 fell by $8.0 \pm 1.3 \%$. Similar changes are seen with exercise in a cold environment. KOSKELA et al. [88] showed that when COPD patients performed an incremental cycle ergometer test at $-20^{\circ} \mathrm{C}$, FEV1 fell by an average of $4-8 \%$ when compared to pre-exercise values in ambient air, as did the maximum duration of exercise and the maximal workload. The latter results, however, conflict with those of SPENCE et al. [89], who demonstrated increased peak exercise performance and decreased end-exercise breathlessness in 19 COPD patients with a mean FEV1 of $1 \mathrm{~L}$ exercising in $-13^{\circ} \mathrm{C}$ conditions.

\section{Bullous lung disease}

An important issue in the COPD patient with severe bullous disease is whether the decrease in ambient pressure at altitude might lead to bullae expansion and pneumothorax. The available literature suggests that this concern may be unwarranted. PARKER and StONEHILL [90] studied nine non-COPD patients with blebs or pulmonary cysts and found that upon rapid decompression to a simulated altitude of $13,110 \mathrm{~m}$, the size of the bleb or cyst increased in only one patient and there were no pneumothoraces. TOMASHEFSKI et al. [91] brought six COPD patients with blebs and bullae to a simulated altitude of 5,488 m at a rate of $304 \mathrm{~m} \cdot \mathrm{min}^{-1}$ and found no radiographic evidence of bullae distention or pneumothoraces. Finally, YANDA and HERSCHENSOHN [92] took four patients with COPD and evidence of air-trapping to a simulated altitude of $5,488 \mathrm{~m}$ and did not find evidence of worsening pulmonary function or pneumothorax. While computed tomography (CT) scanning might provide more accurate assessment of bullae size compared to the conventional radiography used in these studies, the absence of pneumothoraces in these studies is reassuring. The reason for the absence of pneumothoraces in patients with bullous disease has not been elucidated. Bullae may communicate with the airways to a greater extent than expected, allowing for pressure equalisation. In addition, the pressure changes with ascent to altitude $(<50 \mathrm{kPa})$ are less than those seen with scuba diving $(200-300 \mathrm{kPa})$ and, as a result, the pressure gradient for bullae expansion and rupture is much lower.

\section{COPD and secondary pulmonary hypertension}

Patients with severe COPD and baseline hypoxaemia often develop pulmonary hypertension [93, 94]. As discussed below in the section Pulmonary vascular disorders, there is circumstantial evidence to suggest that this might put COPD patients at risk for the development of HAPE or acute right heart failure at high altitude. At altitude, alveolar hypoxia triggers HPV and further increases in $\mathrm{Ppa}$, which may promote oedema formation or increase right heart strain. Cold exposure at high elevations may also contribute to increased pulmonary vascular resistance, although this effect can be blocked with supplemental oxygen administration [95]. Although no studies have examined the impact of hypobaric hypoxia on patients with COPD and pulmonary hypertension, it is reasonable to conclude that the risk of HAPE and acute right heart failure at high altitude will be greater than in patients without secondary pulmonary hypertension.

\section{Work of breathing}

Finally, one must consider how COPD patients will respond to the increased ventilatory demands at high altitude. While the increase in ventilation is easily tolerated in people without lung disease, the question is whether COPD patients with moderate-to-severe disease can sustain the increased ventilatory work and higher oxygen cost of breathing $[96,97]$ for long periods of time. No studies have thus far addressed this issue but tentative conclusions can be drawn from the literature on exercise in COPD patients. MADOR et al. [98] exercised 12 COPD patients with an average FEV1 of $1.8 \mathrm{~L}$ at $60-70 \%$ of their maximal oxygen uptake $\left(V^{\prime} \mathrm{O}_{2}, \max \right)$ until the limits of tolerance and found no evidence of contractile fatigue of the diaphragm. The several minutes' duration of exercise is very short compared to the length of time a COPD patient might spend at altitude. However, the subjects in this study reached a peak minute ventilation of $55.6 \pm 4.1 \mathrm{~L} \cdot \mathrm{min}^{-1}$, significantly higher than the minute ventilation they would generate at rest at altitude. LewIS et al. [99] compared the results of incremental exercise studies in COPD patients and persons with normal spirometry and found that, although the COPD patients had a reduced $V^{\prime} \mathrm{O}_{2}$,max, the slopes of the oxygen uptake versus work-rate relationships were no different. Given the increased oxygen cost of breathing in COPD patients, this finding suggests that the COPD patients were able to handle the increased respiratory load at the expense of oxygen delivery to nonrespiratory muscles. When viewed together, the studies by LewIS et al. [99] and MADOR et al. [98] indicate that COPD patients should be able to sustain resting ventilatory demands at altitude.

\section{Recommendations}

COPD patients whose baseline FEV1 is $<1.5 \mathrm{~L}$ should be assessed prior to high-altitude travel to determine the need for supplemental oxygen. Since data suggest that the resting sealevel $\mathrm{Pa}, \mathrm{O}_{2}$ alone misses a significant number of patients whose $\mathrm{Pa}, \mathrm{O}_{2}$ falls to $<6.7-7.3 \mathrm{kPa}(50-55 \mathrm{mmHg})$ at high altitude, prediction of the $\mathrm{Pa}_{1} \mathrm{O}_{2}$ at altitude should be based on the regression equation provided by DiLLARD et al. [71] which incorporates the patient's FEV1:

$$
\mathrm{Pa}_{1} \mathrm{O}_{2}, \mathrm{Alt}=\left(0.519 \times \mathrm{Pa}_{2} \mathrm{O}_{2}, \mathrm{SL}\right)+(11.85 \times \mathrm{FEV} 1)-1.76
$$

where $\mathrm{Pa}_{1} \mathrm{O}_{2}, \mathrm{Alt}$ is the $\mathrm{Pa}, \mathrm{O}_{2}$ at altitude and $\mathrm{Pa}_{1} \mathrm{O}_{2}, \mathrm{SL}$ is the $\mathrm{Pa}, \mathrm{O}_{2}$ at sea level. Subjects with a predicted $\mathrm{Pa}_{\mathrm{a}, \mathrm{O}_{2}}<6.7-7.3 \mathrm{kPa}(50-$ $55 \mathrm{mmHg}$ ) should travel to high altitude with supplemental oxygen. Having patients breathe in a hypobaric hypoxic environment might provide another useful way to predict the $\mathrm{Pa}, \mathrm{O}_{2}$ at altitude, but this technique is unfeasible in most 
clinical settings and cannot be recommended as part of the pretravel evaluation. Patients should increase the flow rate of oxygen by $2 \mathrm{~L} \cdot \mathrm{min}^{-1}$ when engaging in physical activity. Extreme caution should be taken with patients intending to travel to altitudes $>3,048 \mathrm{~m}$, as no data are available to guide recommendations above this elevation. COPD patients with pre-existing pulmonary hypertension should be counselled against travelling to high altitude due to the theoretical risk of developing HAPE or acute right heart failure. If such travel cannot be avoided, patients should travel with supplemental oxygen and should be placed on nifedipine SR $20 \mathrm{mg}$ b.i.d. through the duration of their stay at altitude, as several studies have shown that nifedipine inhibits HPV at rest and with exercise in COPD [100, 101]. Patients with bullous disease can travel to high altitude but those with a recent spontaneous pneumothorax should wait $\geqslant 2$ weeks following radiographic resolution before undertaking such travel [102]. All COPD patients should remain on their baseline medical regimen while travelling to altitude and should carry an adequate supply of rescue inhalers and prednisone to treat exacerbations that may develop when the patient lacks access to medical care. Finally, it is important to remember that patients with COPD often have comorbid conditions, such as coronary artery disease, which also have the potential to cause complications at high altitude. These recommendations, as well as those for patients with obstructive lung disease, are summarised in table 2 .

\section{Asthma}

As far back as the 1920s, there were indications that asthmatic patients experienced symptomatic improvement at high altitude [103] and much subsequent literature bears this out. For example, VARGAS et al. [104] reported an inverse correlation between a person's residential altitude and the development of asthma or incidence of exacerbations. Similarly, GOURGOULIANIS et al. [105] demonstrated that the prevalence of asthma, number of school days missed and incidence of nocturnal symptoms were lower in children living at 800-1,200 m than among sealevel residents. However, these studies only examined longterm high-altitude residents and, as a result, the findings may not apply to short-term visitors. GoLAN et al. [106] examined the incidence of asthma exacerbations in 203 short-term adventure travellers $(75 \%$ of whom were engaged in high-altitude trekking) and reported worsening asthma control in $20 \%$, as well as 32 patients who said they had their "worst ever" asthma attack. It is not clear, though, that they accounted for the actual altitude attained during their travel or the fact that trips to high altitude often include periods of transit through cities or environments where the air quality is poor. Nevertheless, this study suggests that short-term outcomes may not be consistent with those reported for long-term visitors. In the end, the outcome for short-term visitors may not be as clear as these epidemiological studies suggest and instead probably reflects a complex interplay between several factors that affect asthma control, including the allergen burden at altitude and the effect of cold air, hypoxia, air density and hypocapnia on bronchial responsiveness. Each of these issues is considered below.

\section{Allergen burden}

As a result of hypoxia, lower humidity and other climatic changes, the number of house-dust mites decreases with increasing altitude [5, 6]. This lower mite burden has been shown to decrease peripheral blood T-lymphocyte activation, eosinophil counts [107], house-dust mite-specific immunoglobulin E [108] and markers of eosinophil activation [109, 110]. Asthmatic patients at altitude also demonstrate a lower prevalence of positive skin tests to house-dust mites [111, 112]. These alterations in immune function lead to improvements in bronchial hyperresponsiveness, as several studies have demonstrated decreased responsiveness to histamine, methacholine and adenosine 5'-monophosphate in children following prolonged stays at high altitude [108, 113, 114]. Mite avoidance has also been shown to improve FEV1 and quality of life in paediatric asthma [110], decrease residual volume and air-trapping [115] and decrease peak expiratory flow variability [113, 114]. These studies, however, involved longer-term exposures to high altitude and do not provide adequate guidance regarding asthmatic patients engaged in shorter

\section{TABLE 2 Summary of recommendations for obstructive lung disease patients}

\section{Chronic obstructive pulmonary disease}

For patients with $\mathrm{FEV}_{1}<1.5 \mathrm{~L}$, assess need for supplemental oxygen and administer during stay at high altitude if predicted $\mathrm{Pa}_{\mathrm{a}} \mathrm{O}_{2}<50-55 \mathrm{mmHg}$

Evaluate for comorbid diseases that may also affect the response to altitude

Continue baseline medications and carry supply of rescue inhalers and prednisone for potential exacerbations

Counsel patients with pre-existing pulmonary hypertension against high-altitude travel. If such travel is necessary, prophylax with nifedipine SR 20 mg b.i.d.

Following spontaneous pneumothorax, avoid high-altitude travel until 2 weeks after radiographic resolution

\section{Asthma}

Patients with mild intermittent or mild persistent disease may ascend to altitudes as high as $5000 \mathrm{~m}$

Caution patients with more severe disease against high-altitude travel, particularly into remote areas

Continue baseline medications and carry peak flow meter and supply of rescue inhalers and prednisone for potential exacerbations

Consider using balaclava or bandana over mouth to warm and humidify air in cold environments

\section{Cystic fibrosis}

Assess need for supplemental oxygen in all patients and administer if predicted $\mathrm{Pa}_{\mathrm{a}} \mathrm{O}_{2}<50-55 \mathrm{mmHg}$

If predicted $\mathrm{Pa}_{1} \mathrm{O}_{2}>50-55 \mathrm{mmHg}$, consider supplemental oxygen if $\mathrm{FEV} 1<50 \%$ predicted

Continue pre-existing chest physiotherapy, mucolytics and antibiotics during high-altitude sojourn

FEV1: forced expiratory volume in one second; $\mathrm{Pa}, \mathrm{O}_{2}$ : arterial oxygen tension. $1 \mathrm{mmHg}=0.133 \mathrm{kPa}$. 
exposures. In addition to lower mite burden, other elements of the high-altitude environment that may affect outcomes for asthmatic patients are hypoxia, hypocapnia, air density and air temperature.

\section{Hypoxia}

When the effect of hypoxia is isolated from other aspects of the high-altitude environment, the effects on bronchial reactivity are not clear. Several studies demonstrate that hypoxia increases bronchial responsiveness to methacholine [116, 117], while other studies, using comparable degrees of hypoxic exposure, have shown no change in either the response to methacholine [118, 119] or specific airway resistance [120]. In addition to these effects on bronchial hyperresponsiveness, acute isocapnic hypoxia has also been shown to reduce methacholine-induced symptoms of dyspnoea and chest tightness [121], a result which suggests that asthmatic patients may not perceive when they are developing worsening symptoms at high altitude. Finally, there is some suggestion that acute hypoxia may blunt the response to inhaled bronchodilators, but this result has only been shown in vitro and has not been demonstrated in vivo [122].

\section{Hypocapnia}

As noted earlier, hypoxia triggers an increase in minute ventilation, which, in turn, leads to a fall in the alveolar carbon dioxide partial pressure $\left(P \mathrm{~A}, \mathrm{CO}_{2}\right)$. This response is potentially problematic in asthmatic patients because hypocapnia has been shown to adversely affect airway resistance [123-126]. When Newhouse et al. [123], for example, raised the minute ventilation in five normal males to $30 \mathrm{~L} \cdot \mathrm{min}^{-1}$ and dropped the $\mathrm{PA}_{1} \mathrm{CO}_{2}$ to $2.7-3.3 \mathrm{kPa}(20-25 \mathrm{mmHg})$, mean inspiratory flow resistance increased by $133 \%$ and mean respiratory work increased by $68 \%$ when compared with a minute ventilation that yielded a $\mathrm{PA}, \mathrm{CO}_{2}$ of $6.0-6.7 \mathrm{kPa}(45-50 \mathrm{mmHg})$. Similarly, VAN DEN ELSHOUT et al. [124] examined asthmatic patients with impulse oscillometry and found that a $1.0-\mathrm{kPa}(7.5-\mathrm{mmHg})$ fall in the end-tidal carbon dioxide tension led to a $13.2 \%$ increase in airway resistance and a $45 \%$ fall in airway reactance.

\section{Air temperature}

Inhalation of cold air may also worsen asthma symptoms. Coldair hyperventilation challenge, for example, has been shown to be useful in discriminating between children with and without asthma [127] and to correlate well with nonspecific bronchial reactivity measured by methacholine inhalation challenge [128]. Larger epidemiological studies have also shown that crosscountry skiers, a group of individuals whose training and competition generates high minute ventilation in cold environments, have a higher incidence of asthma and asthma-like symptoms when compared to nonathletic controls [129, 130]. In a smaller study, DURAND et al. [131] demonstrated that up to $50 \%$ of ski mountaineers develop exercise-induced bronchoconstriction following a race and that $73 \%$ are unaware of the problem. Several studies have also demonstrated increased bronchial responsiveness to breathing cool air [132-134] and cooling of the skin [135, 136], although TESSIER et al. [137] reported no increase in bronchial responsiveness to histamine following exercise while breathing cold air. The observed hyperresponsiveness is attenuated by administration of cromolyn sodium [138], acetazolamide [139] and nifedipine [140]. The fact that the latter two medications may block cold-induced bronchial hyperresponsiveness is of particular importance since both medications are used for prophylaxis against high-altitude illness. It is interesting to speculate that their use by asthmatics for this reason may also provide protection against asthma exacerbations.

\section{Air density}

As one ascends to altitude and the barometric pressure falls, air density decreases. Less dense gases have better flow properties through narrow airways and, therefore, one would expect that asthmatic patients might benefit from the lower air density at altitude. While the effects of air density at altitude have not been addressed in the asthma literature, the density issue has received attention in the management of asthma at sea level. Numerous studies have looked at the use of a lowdensity helium-oxygen mixture (heliox) in nonintubated patients with asthma exacerbations and have revealed improvements in dyspnoea and airflow obstruction [141], spirometric parameters such as FVC and FEV1 [142] and delivery of nebulised solutions to the lower airways [143]. Some systematic reviews [144, 145] have concluded, however, that the preponderance of evidence does not yet support the widespread use of heliox in clinical practice. Nevertheless, the effects of heliox at sea level raise the question of whether the lower air density at altitude might be of benefit to asthma patients. At sea level, the density of air is $1.29 \mathrm{~g} \cdot \mathrm{L}^{-1}$, whereas an $80 \% / 20 \%$ heliox mixture has a density of only $0.428 \mathrm{~g} \cdot \mathrm{L}^{-1}$. At an altitude of $5,500 \mathrm{~m}$, where the barometric pressure is roughly half that of sea level, the air density would be $\sim 0.645 \mathrm{~g} \cdot \mathrm{L}^{-1}$, still greater than that of the $80 \% / 20 \%$ heliox mixture at sea level. As a result, an asthma patient might have to ascend to very high elevations before they could experience significant effects from the air density changes similar to that seen with heliox at sea level. As noted above, this issue has not been studied systematically at altitude, nor are there any data concerning whether the lesser density changes seen at lower elevations might be of benefit to asthma patients either during or outside of an exacerbation period.

While the data on house-dust mites, hypoxia, hypocapnia, air density and cold-air inhalation provide insight into how asthma patients will fare upon ascent to high altitude, the ability of these studies to answer that question is limited in two respects. The applicability of the house-dust mite data is limited by the fact that the duration of exposure in those studies was much longer than what many travellers to high altitude will face. The hypoxia and cold air studies used shorter exposures, but many of these studies isolated the effect of one factor on airway reactivity and did not take into account the complete range of climatic conditions asthma patients face at high altitude. For example, the studies on hypoxia and bronchial hyperreactivity used isocapnic hypoxia as the independent variable. This is important for isolating the effect of hypoxia on the airways, but the fact is that asthmatic subjects at high altitude experience hypocapnic hypoxia and often breathe cool air at the same time. Given these limitations, the best information for assessing short-term outcomes of asthma patients at altitude comes from a few field studies in which subjects are tested in the high-altitude environment and all of its associated climatic conditions. 


\section{Field studies on asthmatic patients at altitude}

LOUIE and PARE [146] studied 10 nonasthmatic and five asthmatic patients with mild, well-controlled disease during a trek in the Nepal Himalaya and demonstrated that the asthmatic patients had a mean decrease in their PEFR of $76 \pm 67 \mathrm{~L} \cdot \mathrm{min}^{-1}$ between sea level and their two highest altitudes. Completion of a 200-m run at altitude did not lead to further decrement in PEFR. One problem with this study, however, was the fact that all subjects received either dexamethasone or acetazolamide at the highest elevation, which might have affected bronchial hyperreactivity. CoGO et al. [147] reached a different conclusion than LOUIE and PARE [146]. They studied 11 mild asthmatic patients at sea level and 5,050 $\mathrm{m}$ and demonstrated decreased bronchial reactivity to both hypoosmolar aerosol and methacholine at high altitude. Similarly, AlLEGRA et al. [148] studied 11 mild asthmatic patients on separate trips to $4,559 \mathrm{~m}$ in the Italian Alps and 5,050 $\mathrm{m}$ in the Nepal Himalaya and demonstrated that the bronchial response to hypotonic aerosol was decreased at high altitude. FEV1 fell by a mean of $22 \%$ with hypotonic aerosol at sea level compared to a decrease of only $6.7 \%$ at high altitude. The mechanism behind these changes was not clear but the authors hypothesised that higher levels of cortisol and catecholamines at altitude may play a protective role. These two studies provide some reassurance that asthmatic patients can ascend to moderate altitudes below 5,000 $\mathrm{m}$ without significant adverse effects on short-term function. Caution is necessary in applying these results, however, as these studies only examined outcomes in patients with mild disease. In addition, none of the studies reported other outcomes at high altitude, which might be of importance, such as the frequency of rescue inhaler use or the need for oral steroids to control worsening symptoms.

\section{Recommendations}

Patients with mild-intermittent or mild-persistent asthma can ascend to altitudes as high as 5,000 m. They should maintain their pre-existing medication regimen and should travel with an ample supply of rescue inhalers and oral prednisone to treat any asthma exacerbations that occur in remote areas away from medical attention. Patients should consider travelling with their fixed orifice peak flow meters, since variable orifice meters underestimate flow at higher altitude and with cold [32, $149,150]$. Even if the absolute peak flows are not accurate, however, the trends may provide useful information to guide management. In cold or windy environments, patients should consider protecting the nose and mouth with bandanas or balaclavas to warm and humidify the inhaled air. Due to the lack of data and the lack of medical facilities in many highaltitude regions, patients with more severe disease at baseline should be cautioned against travelling to remote high-altitude regions. If such travel cannot be avoided, aggressive attempts to control the patient's symptoms with high-dose inhaled steroids or even oral steroids should be made prior to such travel (table 2).

\section{Cystic fibrosis}

As the life expectancy and quality of life of cystic fibrosis (CF) patients improves over time, increasing numbers of these patients may travel to high altitude for work or pleasure. As with COPD patients, much of the literature has focused on the impact of hypobaric hypoxia on pulmonary function and their ability to maintain an adequate $\mathrm{Pa}_{1} \mathrm{O}_{2}$. Little data exist regarding other aspects of care in $\mathrm{CF}$ patients, such as the incidence of clinical exacerbations.

The effect of high altitude on pulmonary function in $\mathrm{CF}$ patients is not consistent across studies. FISCHER et al. [151] reported small but statistically significant increases in the FEV1 and FVC at 2,650 $\mathrm{m}$ while THEWs et al. [152] reported no change and Rose et al. [153] demonstrated a slight drop in these values at $3,000 \mathrm{~m}$.

There is consistent evidence, however, that travel to moderate altitudes $(2,000-3,000 \mathrm{~m})$ causes the $\mathrm{Pa}_{\mathrm{a}} \mathrm{O}_{2}$ to fall near to or $<6.7 \mathrm{kPa}(50 \mathrm{mmHg})$. Rose et al. [153] studied 10 patients in a hypobaric chamber and found that the average $\mathrm{Pa}, \mathrm{O}_{2}$ fell from a baseline value of $10.6 \mathrm{kPa}(79.5 \mathrm{mmHg})$ at sea level to $8.0 \mathrm{kPa}$ $(60 \mathrm{mmHg})$ and $6.05 \mathrm{kPa}(45.5 \mathrm{mmHg})$ at simulated altitudes of 2,000 $\mathrm{m}$ and 3,000 $\mathrm{m}$, respectively. FISCHER et al. [151] took 36 patients to an actual altitude of 2,650 $\mathrm{m}$ for a period of $7 \mathrm{~h}$ and found that the median $\mathrm{Pa}_{\mathrm{a}} \mathrm{O}_{2}$ fell from $9.8 \mathrm{kPa}(74 \mathrm{mmHg})$ at $530 \mathrm{~m}$ to $7.1 \mathrm{kPa}(53 \mathrm{mmHg})$ at that altitude. The data also suggest that the more severe the underlying lung disease, the greater the likelihood of significant hypoxaemia; six out of their 11 patients with an FEV $1<50 \%$ predicted sustained a fall in resting $\mathrm{Pa}_{1} \mathrm{O}_{2}$ to $<6.7 \mathrm{kPa}(50 \mathrm{mmHg})$ at $2,650 \mathrm{~m}$, whereas only four of the 20 patients with an FEV1 $>70 \%$ predicted experienced a similar change.

Exercise exacerbates hypoxaemia in these patients. FISCHER et al. [151] exercised subjects at a constant workload of $30 \mathrm{~W}$ for $5 \mathrm{~min}$, during which time the $\mathrm{Pa}_{\mathrm{a}} \mathrm{O}_{2}$ fell to $<6.7 \mathrm{kPa}$ $(50 \mathrm{mmHg})$ in two-thirds of the patients. RYUJIN et al. [154] performed maximal exercise tests without arterial blood gases on $50 \mathrm{CF}$ patients at a lower altitude of $1,500 \mathrm{~m}$ and demonstrated a fall in the mean arterial oxygen saturation from $93 \%$ at rest to $87 \%$ at peak exercise. The magnitude of desaturation correlated with the severity of the patients' preexercise lung function.

Whether the impaired oxygenation is of clinical significance is unknown. Rose et al. [153] and FISCHER et al. [151] both reported that none of their subjects had symptoms of dyspnoea during either the simulated or actual altitude exposure. Similarly, KAMIN et al. [155] exposed $12 \mathrm{CF}$ patients to a simulated altitude of 3,000 $\mathrm{m}$ in a hypobaric chamber and found that $90 \%$ of them tolerated falls in their $\mathrm{Pa}_{\mathrm{a}_{2}} \mathrm{O}_{2}$ to below the $6.7 \mathrm{kPa}$ (50 $\mathrm{mmHg}$ ) threshold. FISCHER et al. [151] also measured Lake Louise AMS scores in their subjects and reported a mean score of $1.0 \pm 0.78$ at the end of the sojourn to high altitude. Given that a Lake Louise AMS score $\geqslant 3$ is necessary to qualify for a diagnosis of AMS and that the maximum score on the assessment used in this study is 15 , this mean score represents only a minor degree of symptoms at high altitude. The lack of symptoms in these studies suggests that, as with COPD patients, chronically hypoxic CF patients may tolerate falls in their $\mathrm{Pa}, \mathrm{O}_{2}$ below the recommended thresholds because they are already somewhat "acclimatised" to the low-oxygen conditions. Each of these studies, however, involved only short exposures to hypobaric hypoxia and, as a result, may underestimate the incidence of AMS or other high altituderelated diseases, which often start much later than the 7-h 
exposure used by FISCHER et al. [151]. SPEECHLY-DICK et al. [156] reported on two CF patients with a pre-travel FEV1 in the 1-L range who developed pulmonary hypertension and cor pulmonale during ski holidays at high altitude. Thus, one must be concerned that more prolonged stays at high altitude may impose significant risks on those patients with more advanced disease. SPEECHLY-Dick et al. [156] also noted that both patients had increased sputum volume on return from high altitude, but aside from their report, there are no systematic studies on sputum production and clinical exacerbations in CF patients at high altitude.

\section{Recommendations}

Unlike the case for COPD, the sea-level hypoxia inhalation test may not be a good predictor of arterial $\mathrm{Pa}_{1} \mathrm{O}_{2}$ at altitude in $\mathrm{CF}$ patients. OADES et al. [157] found the test to be a good predictor of the hypoxic response in teenage children on aircraft (coefficient of correlation 0.76) but reported worse performance at altitude (coefficient of correlation 0.47). FISCHER et al. [151] reported a similarly low coefficient of correlation $\left(\mathrm{r}^{2}=0.5\right)$ in their study of 36 adult cystic fibrosis patients and found that pre-travel spirometric results had better predictive value for determining which patients would desaturate to a significant degree at altitude. Given these data, the current authors recommend including spirometric data in the pre-travel assessment of CF patients for supplemental oxygen. Hypoxia inhalation tests should be performed prior to altitude travel and, in those subjects whose arterial $\mathrm{Pa}_{1} \mathrm{O}_{2}$ falls to $<6.7 \mathrm{kPa}$ (50 $\mathrm{mmHg}$ ), supplemental oxygen should be prescribed. If the patient maintains a $\mathrm{Pa}_{\mathrm{a}} \mathrm{O}_{2}$ above this level but spirometry reveals severe underlying disease (FEV1 $<50 \%$ pred), strong consideration should be given to having these patients travel with supplemental oxygen, particularly in the event of a prolonged stay at altitude. Pre-existing chest physiotherapy programmes, prophylactic antibiotics and mucolytic therapy should also be continued during high-altitude travel (table 2).

\section{PULMONARY VASCULAR DISORDERS}

Two forms of pulmonary vascular disease merit attention: pulmonary hypertension and thromboembolic disease. The latter is a concern whether or not the patient has associated pulmonary hypertension.

\section{Disorders associated with pulmonary hypertension}

There are no systematic studies examining outcomes in patients who ascend to high altitude with pre-existing primary or secondary pulmonary hypertension. Nevertheless, drawing on the current understanding of the pathophysiology of HAPE and numerous case reports in the literature, it is possible to qualitatively assess the risks faced by patients at high altitudes.

As noted earlier, a key pathophysiological feature of HAPE is the exaggerated pulmonary vascular response to acute hypoxia. Exuberant hypoxic pulmonary vasoconstriction leads to large increases in pulmonary arterial and capillary pressures which, in turn, promote the transit of red blood cells, protein and fluid from the vascular space into the pulmonary interstitium and alveolar space [158]. Several case reports suggest that pre-existing pulmonary hypertension may exacerbate this pathophysiology and increase the risk of HAPE. HACKETT et al. [159] reported the occurrence of HAPE in four adults with congenitally absent right pulmonary arteries who ascended to $\geqslant 2,750 \mathrm{~m}$. Cardiac catheterisation in one of these patients revealed a $P$ pa of $44 / 17$ at rest and 75/37 $\mathrm{mmHg}$ after 2 min of mild exercise. Similarly, Rios et al. [160] reported a 10 -yr-old male with an absent right pulmonary artery and baseline $P$ pa of $40 / 20 \mathrm{mmHg}$ who developed repeated episodes of HAPE following ascents to altitudes $>1,500 \mathrm{~m}$, while TORRINGTON [161] described a patient with recurrent HAPE attributable to right pulmonary artery occlusion from granulomatous mediastinitis. While these cases all involve anatomical anomalies associated with secondary pulmonary hypertension, there are also reports of HAPE patients with nonanatomical causes of pulmonary hypertension such as pulmonary embolism [162], anorexigen-induced pulmonary hypertension [163] and Down's syndrome [164]. Interestingly, there is also evidence to suggest that people with chronic pulmonary hypertension from high-altitude residences are also susceptible to HAPE development. DAS et al. [165], for example, has described 10 children with chronic pulmonary hypertension (mean $P$ pa $38 \pm 9 \mathrm{mmHg}$ ) secondary to living at moderate altitudes 1,610-3,050 m, who also developed HAPE with ascents to altitudes of 520-2,500 $\mathrm{m}$ above their residential altitude. Four out of the 10 patients had no underlying cardiopulmonary disease and were presumed to have pulmonary hypertension solely due to their high-altitude residence. WU [166] has also described the case of a Tibetan man with chronic mountain sickness and pulmonary hypertension (mean $P$ pa $38 \mathrm{mmHg}$ ) who developed HAPE upon re-ascent to $4,300 \mathrm{~m}$ following a 12-day respite at sea level. When viewed together, these cases suggest that patients with pre-existing secondary pulmonary hypertension should be considered HAPE susceptible.

There are no studies or case reports involving patients with primary pulmonary hypertension. Given the extensive vascular remodelling that occurs in these patients, one might question whether their altered pulmonary vasculature provides a measure of protection against HAPE. In the absence of any data regarding these patients at altitude, it is difficult to make any firm claims in this regard and the more prudent course would be to consider them at increased risk for HAPE.

The limited literature does not provide any sense of the level of pre-existing pulmonary hypertension necessary to increase the risk of HAPE. In the cases described above, systolic $P$ pa in the $40-\mathrm{mmHg}$ range appeared to be sufficient but the wide range of pressures described in these reports makes it difficult to assign a threshold above which a patient becomes at risk for HAPE. It is likely that there is a continuum of risk determined by the patient's underlying pulmonary vascular resistance, HPV responsiveness, and the rate and height of ascent. No data exist as to whether or not these patients can maintain adequate $\mathrm{Pa}_{1} \mathrm{O}_{2}$ upon ascent to high altitude, but if they are hypoxaemic at sea level, it is likely that they will experience more profound hypoxaemia at higher altitudes.

Finally, one must be aware that HAPE is not the only potential source of complications in patients with pulmonary hypertension travelling to high altitude. Even in cases where overt or subclinical oedema does not occur, a further rise in $P$ pa with acute exposure to high altitude could lead to acute right heart failure or subacute mountain sickness with potentially 
devastating consequences for the patient. Lastly, it is reasonable to speculate that those who choose to live in high-altitude regions may be at greater risk of developing chronic mountain sickness.

\section{Recommendations}

In the absence of systematic studies of patients with pulmonary hypertension at high altitude, the safest advice is to recommend against travel to high altitude. If such travel cannot be avoided, patients must be counselled prior to their trip about how to recognise the symptoms and signs of HAPE. Patients with known pulmonary hypertension should use supplemental oxygen with any time at high altitude regardless of whether or not they have hypoxaemia in room air at sea level. While HAPE is generally seen at altitudes above 3,000 m in a normal population, the current authors recommend using supplemental oxygen for trips at lower elevations (e.g. 2,000 m) as the hypoxic conditions in such environments are sufficient to trigger HPV and further increase $P$ pa. The fact that cases occurred at altitudes as low as 1,700 $\mathrm{m}$ in the DuRMOWICZ [164] series and have been described at altitudes as low as 1,400 $\mathrm{m}$ in other series involving apparently normal individuals [167] lends support to this argument. Finally, if patients with pulmonary hypertension of any aetiology are not on medical therapy for their disorder, they should be placed on prophylactic nifedipine SR, $20 \mathrm{mg}$ b.i.d. for the duration of their stay at altitude as this has been shown to prevent HAPE in susceptible individuals [168]. Sildenafil [169] and tadalafil [170] have also been shown to decrease HPV. Interestingly, in the tadalafil study, dexamethasone was also effective in reducing $P$ pa and HAPE. Thus, phosphodiesterase- 5 inhibitors and corticosteroids offer reasonable alternatives to calcium-channel blockers if necessary (table 3).

\section{Pulmonary thromboembolic disease}

Regardless of whether or not they have pulmonary hypertension, patients with a history of venous thromboembolism deserve further consideration. Specifically, the question is whether such patients are susceptible to further thromboembolic events at high altitude. Since there are practically no systematic studies in the literature which address thromboembolic risks at high altitude, only limited conclusions can be drawn from case reports and studies of coagulation parameters in hypobaric or hypoxic environments.
One of the few systematic attempts to evaluate the risk of thromboembolism at altitude is the study by ANAND et al. [171] who retrospectively reviewed the records of 20,257 hospital admissions in India in a 3-yr period and compared the incidence of thromboembolism between patients from high and low elevations. They found 46 cases of vascular thrombosis (44 venous and two arterial) among 1,692 admissions from high-altitude areas and 17 cases from lowaltitude regions and calculated the odds ratio for thromboembolic events at high altitude to be 30.5. Because the subjects in this study spent a mean duration of 10.2 months at high altitude prior to admission, this retrospective study is limited in its extension to the risks associated with shorter sojourns to high altitude.

The study by ANAND et al. [171] is the only study in the literature to use thromboembolic events as the primary outcome measure of the study. The majority of studies on the risk for thromboembolic events at altitude have instead examined changes in various coagulation parameters as surrogate measures for assessing this risk. An examination of these different studies does not reveal clear evidence of increased thrombotic risk at high altitude. The literature contains conflicting results about the effects of acute hypoxic exposure on platelet function. SHARMA [172] reported increased platelet counts following ascent above 3,000 $\mathrm{m}$ while other studies reported either a decrease [173-175] or no change in these levels [176]. Similar conflicting results have been demonstrated for bleeding times [177, 178]. Regarding other components of the coagulation system, studies consistently show that the activated partial thromboplastin time is shorter during acute hypoxic exposures [176, 179, 180] but reveal conflicting data with regard to other biochemical markers of coagulation activity. For example, MANNUCCI et al. [181] report an increase in inhibitors of the fibrinolytic pathway while BARTSCH et al. [180] provide evidence of activation of the fibrinolytic system. Similarly, BENDZ et al. [182] report increased concentrations of thrombin antithrombin-III complexes and prothrombin fragment 1+2, two markers of thrombin formation, while BARTSCH et al. [183] demonstrate that thrombin and fibrin formation were not increased in climbers ascending to $4,559 \mathrm{~m}$. The reasons for the conflicting data include the different numbers of subjects, the environmental settings (hypobaric chamber versus actual ascent), care in blood sampling so as not to activate ex vivo coagulation and

\section{TABLE 3 Summary of recommendations for pulmonary vascular disease patients}

\section{Pulmonary hypertensive disorders}

Counsel patients against high-altitude travel

If high-altitude travel cannot be avoided, counsel patients about the risks, symptoms and signs of HAPE

Administer supplemental oxygen for trips above $2000 \mathrm{~m}$ even in patients not on supplemental oxygen at baseline

For patients not on pre-existing medical therapy, prophylax with nifedipine SR $20 \mathrm{mg}$ b.i.d.

Thromboembolic disease

Continue any pre-existing anticoagulation regimen during high-altitude sojourn with close follow-up of INR before and after trip

Do not initiate new anticoagulation prescription in patients not on a pre-existing regimen

Discontinue oral contraceptives in females with pre-existing coagulopathy

Avoid immobility and dehydration

HAPE: high-altitude pulmonary oedema; INR: international normalised ratio. 
durations of stay at altitude in these various studies. The fact that the studies examine a large number of biochemical markers in what is an exceptionally complex coagulation pathway further increases the possibility of conflicting results and false-positive findings.

An additional problem with using these studies to address whether patients with a prior history of thromboembolism are at risk for further events at high altitude is the fact that the majority of these studies examined healthy individuals with no underlying coagulopathy or prior thrombotic events. A recent study by SCHREIJER et al. [184] suggests that the presence of underlying coagulopathy may, in fact, affect the response to high altitude. They examined 71 healthy volunteers during an actual 8-h flight with cabin pressures equivalent to 1,800 $2,100 \mathrm{~m}$, and found increased levels of thrombin-antithrombin complexes after air travel, compared with following the nonhypoxic exposures. Of note, the greatest changes were noted in those volunteers with the factor $\mathrm{V}$ Leiden mutation who used oral contraceptives, suggesting that the presence of a pre-existing coagulopathy may be associated with increased risk for thromboembolism at high altitude.

This result is particularly intriguing when viewed in light of the case reports of thromboembolic events at high altitude. Many cases of nonlethal thromboembolic events, such as pulmonary embolism [162], deep venous thrombosis with multiple pulmonary emboli [185] and central nervous system venous thromboses [186-188] have been described at high altitude. In a significant percentage of these and other cases, the affected individual was found to have some underlying predisposition to coagulopathy such as oral contraceptive use [185], protein C deficiency [186], hyperhomocysteinaemia [189] or S-C haemoglobinopathy [190]. Keeping in mind the problems involved in using case studies to determine causality, these cases and the data from SCHREIJER et al. [184] suggest that it is only the combination of underlying coagulopathy and altitude exposure that increases the risk for thromboembolic events at altitude.

\section{Recommendations}

In patients with a history of venous thromboembolism, the risk for recurrent events upon re-ascent to high altitude may be related to the presence of an underlying coagulopathy. In patients in whom no underlying risk factor for thromboembolism has been identified, there does not appear to be an increased risk for further thromboembolic events at high altitude. Conversely, in patients in whom an underlying coagulopathy such as the factor $\mathrm{V}$ Leiden mutation or protein $\mathrm{C}$ deficiency has been identified, the risk for future thromboembolic events at altitude may, in fact, be elevated, particularly if the patient also uses oral contraceptive medications.

Patients with a history of venous thromboembolism who ascend to high altitude should continue any therapeutic regimen already initiated at sea level. Increasing altitude has been shown in a retrospective analysis [191] to be a risk factor for a subtherapeutic international normalised ratio and, as a result, close follow-up of a patient's anticoagulation status is warranted before and after a trip to high altitude. If a patient has finished a prescribed period of anticoagulant therapy prior to an ascent, there appears to be no indication that therapy should be resumed, unless special aspects of the trip to high altitude present known thromboembolic risks. Females with underlying coagulopathy and oral contraceptive use should strongly consider discontinuing the oral contraceptives during their high-altitude exposure. In the event of long plane flights, bus rides or other activities with a high degree of immobility, dehydration, or venous occlusion (e.g. backpacking), patients with previous venous thromboembolism should be advised on strategies to avoid these risks (hydration, regular movement, calf exercises, etc.) or be considered for low-dose aspirin during these times. Those with secondary pulmonary hypertension due to thromboembolic disease should be evaluated and managed as described above with regard to the pulmonary hypertensive disorders (table 3 ).

\section{VENTILATORY DISORDERS}

There are several different types of ventilatory disorders that might affect the response to high altitude, including daytime obesity hypoventilation, sleep apnoea, ventilatory control disorders and neuromuscular disorders. For each of these conditions, few studies have examined how patients with the particular disorder fare at altitude. However, by drawing on the pathophysiological consequences of these disorders, it is possible to reach conclusions about the risks these patients face at high altitude.

\section{Obesity hypoventilation}

Patients with obesity-hypoventilation syndrome are at increased risk for developing pulmonary hypertension and right heart failure [192, 193]. As noted above, multiple case reports suggest pre-existing pulmonary hypertension puts this class of patients at risk for the development of HAPE. Even if such patients do not develop HAPE, the greater hypoxaemia may generate a sufficient rise in $P$ pa to induce acute right heart failure and worsening hypoxaemia. This effect may be even possible at the moderate altitudes experienced in aircraft [194].

Obesity-hypoventilation patients are also at increased risk for the development of AMS, as several studies have shown that obesity and nocturnal hypoxaemia are risk factors for the development of this syndrome [195-198]. Ri-Li et al. [195] exposed nine obese and 10 nonobese males to a simulated altitude of 3,658 $\mathrm{m}$ in a hypobaric chamber and showed that the average Lake Louise AMS score increased more rapidly for obese males. In addition, after $24 \mathrm{~h}, 78 \%$ of the obese males had AMS scores of $\geqslant 4$ while only $40 \%$ of the nonobese males had scores at or above this level. This $78 \%$ incidence of AMS in the obese population far exceeds that for healthy individuals travelling to high altitudes [40, 199, 200].

There are also data to suggest that obese patients, independent of whether or not they have obesity hypoventilation, are at risk for complications from prolonged stays at high altitude. LuPIHERRERA et al. [201] studied 20 obese patients with an average weight of $93 \pm 15 \mathrm{~kg}$ who had been living at 2,240 $\mathrm{m}$ and demonstrated that $80 \%$ of these individuals had pulmonary arterial hypertension. Similarly, VALENCIA-FLORES et al. [202] studied 57 obese patients living at a mean altitude of 2,248 m with a mean body mass index of $47.1 \pm 10 \mathrm{~kg} \cdot \mathrm{m}^{-2}$ and found that $96 \%$ of these patients had systolic $P$ pa $\geqslant 30 \mathrm{mmHg}$. 


\section{Recommendations}

Because of the high risk of right ventricular decompensation at high altitude, patients with obesity-hypoventilation should be counselled against high-altitude travel. If such travel is necessary, patients should be provided with supplemental oxygen for daytime and nocturnal use. These patients should also be counselled regarding the recognition and management of AMS [35] and strong consideration should be given to acetazolamide for AMS prophylaxis, since it is an effective ventilatory stimulant both in the awake and sleep state [203]. Limited data from old case series suggest that progesterone therapy may be effective at improving daytime ventilation in this group of patients at sea level $[204,205]$. Other studies have also suggested that progesterone improves waking blood gases without improving nocturnal airway obstruction in patients with concurrent obstructive sleep apnoea [206, 207]. If patients are already taking the medication at sea level, it would be reasonable to continue this at altitude but a new prescription of the medication would not be recommended specifically for high-altitude travel, because the medication has never been studied in this situation. Finally, patients who use continuous positive airway pressure (CPAP) treatment should travel with their units when they go to high altitude, as CPAP use should limit the nocturnal desaturation that can predispose to cardiopulmonary complications. Patients should be aware that unless their CPAP machine has pressurecompensating features, it may not actually deliver the set pressure at high altitude [208]. In such cases, the patient should be instructed to use a higher level of CPAP throughout their trip. The extent to which the set pressure should be adjusted in noncompensating machines can be estimated from equations provided by FrOMM JR et al. (table 4) [208].

\section{Obstructive and central sleep apnoea}

Given its increasing prevalence in the general population, large numbers of obstructive sleep apnoea patients can be expected to travel to high altitude for work or pleasure. Outcomes data at altitude for this group of patients are limited and conflicting in nature. BURGESs et al. [209] studied 14 healthy individuals during an ascent to $5,050 \mathrm{~m}$ and found that the obstructive sleep apnoea index in rapid eye movement sleep fell from $5.5 \pm 6.9$ to $0.1 \pm 0.3 \cdot \mathrm{h}^{-1}$, while NETZER and STROHL [210] studied six healthy individuals during an ascent of Aconcagua in the Andes and found that the total number of obstructive apnoeas and hypopnoeas increased at $4,200 \mathrm{~m}$ relative to their preascent baseline. The applicability of these studies to the population with obstructive sleep apnoea at sea level is questionable, as these studies examined only small numbers of healthy individuals whose baseline apnoea/hypopnoea indices were below the threshold for a diagnosis of obstructive sleep apnoea. The reason why the number of obstructive events would possibly decrease at altitude is unclear. It may relate to the decreased air density at altitude or the fact that the hypoxic ventilatory response overrides other influences that contribute to obstructive events at sea level. Obstructive sleep apnoea patients with significant arterial desaturation at sea level would be expected to have more profound arterial desaturation during apnoeic periods at high altitude, but there are no data on this issue. Finally, obstructive sleep apnoea patients with daytime hypoxaemia are at risk for diurnal pulmonary hypertension [211-214], which, as noted above, might place them at risk for developing HAPE. Unfortunately, there are no data regarding whether this actually occurs at high altitude.

\section{TABLE 4 Summary of recommendations for ventilatory disorders}

\section{Obesity hypoventilation}

Counsel against high-altitude travel

If high-altitude travel cannot be avoided, administer supplemental oxygen for day- and night-time use

Counsel patients about the risks for and symptoms of AMS and prophylax with acetazolamide $125 \mathrm{mg}$ or $250 \mathrm{mg}$ b.i.d.

In patients with pre-existing CPAP prescription, travel to altitude with CPAP unit and make necessary adjustments in set pressure for machines lacking pressure compensation

\section{Obstructive and central sleep apnoea}

Travel to altitude with CPAP machine and make necessary adjustments in set pressure for machines lacking pressure compensation

For patients with central sleep apnoea, consider acetazolamide $250 \mathrm{mg}$ b.i.d.

Continue pre-existing nocturnal oxygen therapy during high-altitude sojourn

Evaluate patients with daytime hypoxaemia for the presence of pulmonary hypertension and, if present, prophylax with nifedipine SR $20 \mathrm{mg}$ b.i.d.

Optimise heart-failure regimen for patients with central sleep apnoea due to cardiomyopathy

\section{Prior carotid artery surgery}

Avoid high-altitude travel in patients with preceding bilateral carotid resection

If travel cannot be avoided administer supplemental oxygen

Assess hypoxic ventilatory response in patients with prior history of carotid endarterectomy and administer supplemental oxygen if response is suppressed

\section{Neuromuscular disorders}

Screen for the presence of sleep-disordered breathing and, if present, treat with bilevel positive airway pressure at altitude

Screen for baseline hypoventilation and, if present, travel to high altitude with bilevel positive airway pressure

Administer nocturnal supplemental oxygen in patients with history of nocturnal desaturations, but avoid "over-oxygenation" to prevent suppression of ventilatory drive

Screen kyphoscoliosis patients for pre-existing pulmonary hypertension and, if present, administer supplemental oxygen and prophylax with nifedipine SR 20 mg b.i.d.

Counsel patients with bilateral diaphragmatic paralysis against high-altitude travel; If travel cannot be avoided, administer bilevel positive airway pressure 
Central sleep apnoea is present in certain patients at sea level, such as those with severe cardiomyopathies. There are no studies of this population at high altitude. However, there is strong reason to believe that the degree of central sleep apnoea would remain the same or get worse at altitude. Numerous studies have shown that central sleep apnoea and periodic breathing are common phenomena at high altitude and that their severity increases as one moves to higher elevations [209, 215-217]. BURGESS et al. [209], for example, demonstrated that the central respiratory disturbance index increased from $4.5 \pm 7.7$ at $1,400 \mathrm{~m}$ to $55.7 \pm 54.4$ at an altitude of $5,050 \mathrm{~m}$. This study examined healthy individuals but it is reasonable to argue that the same pattern might be seen in patients with preexisting central sleep apnoea at sea level. To the extent that these patients desaturate at sea level, they can be expected to have profound desaturation events at high altitude.

\section{Recommendations}

Patients with obstructive or central sleep apnoea at sea level should travel to high altitude with their CPAP equipment. As noted above, if the equipment does not have pressurecompensating features, a higher level of pressure will be necessary during the stay at high altitude. For those with predominantly central sleep apnoea, acetazolamide can be used to mitigate the sleep-disordered breathing [218-221]. Patients using supplemental oxygen at night at sea level should continue to do so at altitude. Those patients with daytime hypoxaemia should be evaluated with echocardiography for the presence of pulmonary hypertension and, if it is present, be treated with nifedipine through the duration of their stay at altitude. Finally, because of the recognised association between central sleep apnoea and heart failure $[222,223]$, patients with this combination of disorders should be cautioned that their heart failure may be the primary source of their limitation at altitude (table 4).

\section{Disorders that affect control of ventilation}

Little data exist regarding patients with disorders that affect control of ventilation. One group for whom some data are available is patients with impaired ventilatory control following carotid endarterectomy (CEA). CEA can damage or obliterate the carotid body, a vital component of HVR [224]. RoEGGLA et al. [225] performed blood gas analysis on four patients at rest at $171 \mathrm{~m}$ and $1,600 \mathrm{~m}$ before and after unilateral CEA and demonstrated that after surgery $\mathrm{Pa}_{1} \mathrm{O}_{2}$ at $1,600 \mathrm{~m}$ was significantly lower and the carbon dioxide arterial tension was unchanged when compared to the pre-surgery values. This result, which strongly suggests that the HVR is impaired in these individuals, agrees with results of earlier studies [226228] which examined patients whose carotid bodies were denervated during endarterectomy or who underwent bilateral carotid resection for asthma. In these cases, patients were noted to have no increase in their ventilation following sustained hypoxia when tested weeks to years following their surgery. Given that an impaired HVR predisposes to several forms of altitude illness [229-231], this group of patients may be at risk for problems at high altitude and may also be unable to appreciate warning signs of impending illness. CHANG et al. [232], for example, describe a 12-yr-old male who underwent bilateral carotid resection for management of asthma and upon hypoxic challenge became cyanotic and disoriented but lacked any subjective sensations of discomfort or dyspnoea. Two case reports of patients who developed AMS and HACE, respectively, following neck irradiation [233, 234] suggest this issue might be a concern in any patient following neck surgery or irradiation, rather than being limited to patients who have undergone a carotid artery procedure.

\section{Recommendations}

Patients who have undergone bilateral carotid resection should not undertake travel to high altitude. If such travel cannot be avoided, they must travel with supplemental oxygen. Since carotid denervation or carotid body sacrifice are not consistent outcomes in CEA [235], patients who have undergone this or other carotid artery surgery should be screened prior to highaltitude travel. If they are found to have an impaired HVR, supplemental oxygen should be provided for their journey. Another option is the use of respiratory stimulants that enhance central chemoreceptor sensitivity, such as acetazolamide, theophylline and progesterone. Although there are no studies validating this approach at high altitude in these particular patients, central apnoea and periodic breathing in other diseases can be ameliorated by these drugs (table 4 ) [221, 236].

\section{Neuromuscular disease}

Neuromuscular diseases, such as myotonic or Duchenne's muscular dystrophies, diaphragmatic paralysis, kyphoscoliosis, amyotrophic lateral sclerosis and Guillain-Barré syndrome can adversely affect pulmonary function and cause hypoxaemia, alveolar hypoventilation or sleep disturbances [237]. None of these diseases have been studied in a high-altitude environment but the literature on several of these entities suggests ways in which these patients may develop problems at high altitude.

Patients with Parkinson's disease [238] and myotonic dystrophy [239], for example, have blunted hypoxic ventilatory responses at sea level, which, as noted above, is a possible risk factor for AMS and HAPE. Myotonic dystrophy patients, as well as those with Duchenne's muscular dystrophy, have obstructive sleep apnoea and significant nocturnal hypoxaemia, with reported mean nadir oxygen saturations as low as $74-75 \%$ [240-242]. Given this degree of hypoxaemia at sea level, these patients might be expected to have even more profound desaturation events at high altitude.

Patients with kyphoscoliosis also can have central apnoea and nocturnal hypoxaemia, the severity of which does not correlate with the extent of their thoracic deformity or impairment in pulmonary function [243]. In addition, given that pulmonary hypertension and cor pulmonale are common in severe cases of kyphoscoliosis [244, 245], these patients might be prone to HAPE. These haemodynamic changes, even without HAPE, can cause right-to-left interatrial shunts at sea level [246], which could lead to profound hypoxaemia at high altitude.

Finally, many patients with neuromuscular disorders have daytime hypoventilation and require various forms of support such as nocturnal bilevel positive airway pressure or a daytime sip ventilator $[247,248]$. They might not be able to raise their ventilation in response to the hypoxic conditions at high altitude and thus may develop profound arterial hypoxaemia and hypercapnia. Even if they do not have baseline hypercapnia, 
patients with bilateral diaphragmatic paralysis or bilateral phrenic neuropathy often have arterial hypoxaemia, particularly when supine $[249,250]$. As a result, they may desaturate to a significant extent at altitude, particularly during sleep.

\section{Recommendations}

Patients with neuromuscular disorders should be screened for the presence of sleep apnoea prior to travelling to high altitude and should travel with bilevel positive airway pressure if sleep-disordered breathing is detected. Patients with significant nocturnal desaturations at sea level should sleep with supplemental oxygen as well. Those with severe kyphoscoliosis should be screened for pulmonary hypertension and, if present, should be placed on supplemental oxygen as well as prophylactic nifedipine during their stay at high altitude. Patients with hypoventilation at sea level must travel to high altitude with noninvasive ventilatory support such as bilevel positive airway pressure or a sip ventilator. Extreme care should be taken to ensure that patients with neuromuscular disorders and chronic hypoventilation do not receive excessive supplemental oxygen, which may lead to progressive hypercapnia [247]. Finally, due to the risk of worsening hypoxaemia, patients with bilateral diaphragmatic paralysis should be counselled against travel to high altitude but, if such travel cannot be avoided, they should travel with noninvasive means of ventilatory support (table 4).

\section{INTERSTITIAL LUNG DISEASES}

Of all the disorders discussed in the present review, interstitial lung disease (ILD) has the least data available to guide clinical practice with travel to high altitude. Only two studies have examined changes in arterial oxygenation with simulated ascent to high altitude. SECCOMBE et al. [74] exposed 15 patients with unspecified types of ILD to an $\mathrm{F} \mathrm{I}_{2} \mathrm{O}_{2}$ of 0.15 (corresponding to a simulated altitude of $2,438 \mathrm{~m}$ ) and found that the $\mathrm{Pa}_{\mathrm{a}} \mathrm{O}_{2}$ fell from a sea-level average of $11 \pm 0.9 \mathrm{kPa}(84 \pm 6.8 \mathrm{mmHg})$ to a simulated high-altitude average of $6.8 \pm 1.0 \mathrm{kPa}(51 \pm 7.5 \mathrm{mmHg})$ at rest and $5.5 \pm 0.7 \mathrm{kPa}(41 \pm 5 \mathrm{mmHg})$ after walking $50 \mathrm{~m}$. CHRISTENSEN et al. [251] studied 17 patients with a heterogeneous group of restrictive disorders and found that exposure to a simulated altitude of $2,438 \mathrm{~m}$ caused the $\mathrm{Pa}, \mathrm{O}_{2}$ to fall from a sealevel average of $10 \pm 1.6 \mathrm{kPa}(78 \pm 12 \mathrm{mmHg})$ to $6.5 \pm 1.1 \mathrm{kPa}$ $(49 \pm 8 \mathrm{mmHg})$ at rest and $5.1 \pm 0.9 \mathrm{kPa}(38 \pm 6.8 \mathrm{mmHg})$ following 20-W exercise. They also found that supplemental oxygen at $2 \mathrm{~L} \cdot \mathrm{min}^{-1}$ at rest and $4 \mathrm{~L} \cdot \mathrm{min}^{-1}$ with exercise was sufficient to maintain $\mathrm{Pa}_{1} \mathrm{O}_{2}>6.7 \mathrm{kPa}(50 \mathrm{mmHg})$. In terms of whether the patients developed symptoms as a result of their hypoxaemia, SECCOMBE et al. [74] reported a statistically significant increase in the Borg dyspnoea score in their subject group, while CHRISTENSEN et al. [251] only noted that two subjects terminated their exercise study after only $2 \mathrm{~min}$ due to dyspnoea. CHRISTENSEN et al. [251] provide a regression equation, which takes into account the sea-level $\mathrm{Pa}_{\mathrm{a}} \mathrm{O}_{2}$ and TLC (measured as \% pred). This model only accounted for $77 \%$ of the variance in $\mathrm{Pa}_{\mathrm{a}} \mathrm{O}_{2}$ at $2,438 \mathrm{~m}$ and has not been validated in a subsequent study.

At present, there are no data, such as baseline pulmonary test results, which provide insight into which patients with ILD are susceptible to illness at high altitude. There are also no data regarding changes in pulmonary mechanics or pulmonary vascular responses in ILD. Given that many of these patients develop secondary pulmonary hypertension, patients with elevated pulmonary arterial pressures at sea level might be at risk for developing HAPE at high altitude.

\section{Recommendations}

Patients with ILD should undergo evaluation prior to travel to high altitude to determine the need for supplemental oxygen. It would be acceptable to start with the regression equation proposed by CHRISTENSEN et al. [251] for the predicted $\mathrm{Pa}_{\mathrm{a}} \mathrm{O}_{2}$ at 2,438 m ( $\mathrm{Pa}, \mathrm{O}_{2}$, Pred $)$ :

$$
P a, \mathrm{O}_{2}, \text { Pred }=0.74+\left(0.39 \times \mathrm{Pa}_{2} \mathrm{O}_{2}, \mathrm{SL}\right)+(0.033 \times \mathrm{TLC})
$$

Subjects in whom the predicted $\mathrm{Pa}_{1} \mathrm{O}_{2}$ falls to $<6.7-7.3 \mathrm{kPa}$ (50-55 mmHg) should receive supplemental oxygen. Since this equation has not been validated in larger studies and does not explain all of the variance between sea-level and high-altitude $\mathrm{Pa}_{1} \mathrm{O}_{2}$, patients deemed to be at high risk for hypoxaemia at altitude should undergo formal testing in a hypobaric chamber or with hypoxic gas breathing as described by GONG JR et al. [77]. Given the association between many forms of ILD and pulmonary hypertension, echocardiography should be performed prior to high-altitude travel in patients for whom the presence or absence of pulmonary hypertension has not been documented. Patients with secondary pulmonary hypertension should avoid travel to high altitude. If such travel is necessary, these patients should use supplemental oxygen and be placed on nifedipine for HAPE prophylaxis (table 5).

\section{PNEUMOTHORACES AND PLEURAL DISORDERS}

As noted earlier in the present review, the available data suggest that patients with bullous lung disease can ascend to high altitude without risk of bullae expansion or pneumothorax. The situation is different for patients with pneumothoraces. As such air collections do not communicate with the environment, there is a high risk they will expand at altitude and cause increasing respiratory difficulty and perhaps even tension pneumothorax [252, 253]. Guidelines of the Aerospace Medical Association [76] state that patients with pneumothorax or recent chest surgery should wait 2 3 weeks after successful drainage of the pneumothorax prior to air travel. Perhaps the only prospective evaluation of the proper timing for exposure to hypobaric conditions is that carried out by CHEATHAM and SAFESAK [102], who followed 12 consecutive patients with recent traumatic pneumothorax wishing to fly by commercial airline. Ten patients waited at least 14 days after radiographic resolution and experienced no in-flight symptoms while one of two patients who flew earlier developed a recurrent pneumothorax in flight. The second patient had symptoms consistent with pneumothorax but no radiographs were obtained to confirm the diagnosis. No data exist on outcomes at high altitude for patients with other forms of lung disease that predispose to pneumothoraces, such as lymphangioleiomyomatosis or pneumocystis jiroveci pneumonia.

\section{Recommendations}

Patients with recent pneumothorax or thoracic surgical procedures should wait a minimum of 2 weeks following radiographic resolution of intrapleural air collections before 


\section{TABLE 5 Summary of recommendations for interstitial lung disease and pleural disorders}

Interstitial lung disease

Assess need for supplemental oxygen and administer during stay at high altitude if predicted $\mathrm{Pa}_{\mathrm{a}_{2}} \mathrm{O}_{2}<50-55 \mathrm{mmHg}$

Screen patients for pre-existing pulmonary hypertension and, if present, administer supplemental oxygen and prophylax with nifedipine SR $20 \mathrm{mg}$ b.i.d.

Pleural disorders

After pneumothorax or thoracic surgery, wait 2 weeks after radiographic resolution of intrapleural air collections before undertaking high-altitude travel

With persistent pneumothorax or bronchopleural fistula, travel to altitude with chest tube or Heimlich valve in place

Consider screening patients at high risk for secondary spontaneous pneumothorax for the presence of occult pneumothorax with CT scan prior to high-altitude travel

$\mathrm{Pa}, \mathrm{O}_{2}$ : arterial oxygen tension; $\mathrm{CT}$ : computed tomography. $1 \mathrm{mmHg}=0.133 \mathrm{kPa}$

ascent to high altitude. If a pneumothorax is still present or other intrapleural pathology exists such as a bronchopleural fistula, ascent should only be undertaken if a chest tube or oneway Heimlich valve are in place. It may be prudent to screen patients with disorders associated with secondary spontaneous pneumothoraces for the presence of occult pneumothorax with plain radiograph or $\mathrm{CT}$ scan prior to ascent to high altitude (table 5).

\section{DRUG PROPHYLAXIS OF HIGH-ALTITUDE ILLNESS IN PATIENTS WITH SEVERE LUNG DISEASE}

The drugs available for prophylaxis of AMS, HAPE and HACE are agents with which most pulmonologists are already familiar: acetazolamide; salmeterol; dexamethasone; theophylline and phosphodiesterase- 5 inhibitors; and calcium-channel blockers. With the exception of acetazolamide, there are no special circumstances to warrant caution in patients with lung disease beyond those already established for these drugs. For patients with lung disease characterised by severe ventilatory limitation (FEV1 $<25 \%$ pred), however, one should use caution in the dosing of acetazolamide. By inhibiting renal carbonic anhydrase, acetazolamide creates a mild metabolic acidosis which stimulates ventilation. With doses greater than $2 \mathrm{mg} \cdot \mathrm{kg}^{-1}$, however, there can be significant red cell carbonic anhydrase inhibition, which can impair carbon dioxide excretion [203]. In the setting of increased ventilation needs and limited ventilatory reserves, this carbon dioxide retention may lead to worsened dyspnoea and/or respiratory failure [254]. In such patients, acetazolamide should be limited to $125 \mathrm{mg}$ b.i.d. or an alternative agent such as dexamethasone should be used [35].

\section{CONCLUSIONS}

The present review article has examined the manner in which a variety of lung diseases may be affected by high altitude and whether or not patients with such diseases are at risk for altitude-related illnesses. While larger outcome studies involving such patients are lacking at this time, it is possible to draw on an understanding of the pathophysiology of each type of disease as well as on a limited number of smaller studies, case reports and other forms of indirect evidence and make tentative conclusions about the risks faced by these patients when they travel to high altitude. Pre-existing lung disease does not always preclude travel to high altitude. In many cases, such travel may be safely carried out provided a thorough pre-travel evaluation has been conducted and adequate prophylactic measures have been put in place to prevent altitude illness or worsening of the underlying disease.

\section{REFERENCES}

1 Climbing Statistics. www.nps.gov/mora/climb/cl_stats. htm. Date last updated: April 13 2006. Date last accessed: September 12006.

2 Fast Facts. Vail Ski Resorts Media Guide. www.mediaguide.snow.com/info/vail/facts.asp. Date last updated August 1 2006. Date last accessed: April 142006.

3 West JB, Lahiri S, Maret KH, Peters RM Jr, Pizzo CJ. Barometric pressures at extreme altitudes on Mt. Everest: physiological significance. J Appl Physiol 1983; 54: 1188-1194.

4 Ward MP, Milledge JS, West JB. High Altitude Medicine and Physiology. 2nd Edn. London, Chapman and Hall Medical, 1995.

5 Spieksma FT, Zuidema P, Leupen MJ. High altitude and house-dust mites. BMJ 1971; 1: 82-84.

6 Vervloet D, Penaud A, Razzouk H, et al. Altitude and house dust mites. J Allergy Clin Immunol 1982; 69: 290-296.

7 Bishop GA, Morris JA, Stedman DH, et al. The effects of altitude on heavy-duty diesel truck on-road emissions. Environ Sci Technol 2001; 35: 1574-1578.

8 Basu CK, Selvamurthy W, Bhaumick G, Gautam RK, Sawhney RC. Respiratory changes during initial days of acclimatization to increasing altitudes. Aviat Space Environ Med 1996; 67: 40-45.

9 Wagner PD, Gale GE, Moon RE, Torre-Bueno JR, Stolp BW, Saltzman HA. Pulmonary gas exchange in humans exercising at sea level and simulated altitude. $J$ Appl Physiol 1986; 61: 260-270.

10 Wagner PD, Sutton JR, Reeves JT, Cymerman A, Groves BM, Malconian MK. Operation Everest II: pulmonary gas exchange during a simulated ascent of Mt. Everest. J Appl Physiol 1987; 63: 2348-2359.

11 Dempsey JA, Harms CA, Ainsworth DM. Respiratory muscle perfusion and energetics during exercise. Med Sci Sports Exerc 1996; 28: 1123-1128.

12 Harms CA, Babcock MA, McClaran SR, et al. Respiratory muscle work compromises leg blood flow during maximal exercise. J Appl Physiol 1997; 82: 1573-1583.

13 West JB, Hackett PH, Maret KH, et al. Pulmonary gas exchange on the summit of Mount Everest. J Appl Physiol 1983; 55: 678-687. 
14 Torre-Bueno JR, Wagner PD, Saltzman HA, Gale GE, Moon RE. Diffusion limitation in normal humans during exercise at sea level and simulated altitude. J Appl Physiol 1985; 58: 989-995.

15 Mason NP, Petersen M, Melot C, et al. Serial changes in nasal potential difference and lung electrical impedance tomography at high altitude. J Appl Physiol 2003; 94: 2043-2050.

16 Cremona G, Asnaghi R, Baderna P, et al. Pulmonary extravascular fluid accumulation in recreational climbers: a prospective study. Lancet 2002; 359: 303-309.

17 Jaeger JJ, Sylvester JT, Cymerman A, Berberich JJ, Denniston JC, Maher JT. Evidence for increased intrathoracic fluid volume in man at high altitude. J Appl Physiol 1979; 47: 670-676.

18 Hultgren HN, Kelly J, Miller H. Pulmonary circulation in acclimatized man at high altitude. J Appl Physiol 1965; 20: 233-238.

19 Canepa A, Chavez R, Hurtado A, Rotta A, Velasquez T. Pulmonary circulation at sea-level and at high altitudes. $J$ Appl Physiol 1956; 9: 328-336.

20 Kronenberg RS, Safar P, Lee J, et al. Pulmonary artery pressure and alveolar gas exchange in man during acclimatization to $12,470 \mathrm{ft}$. J Clin Invest 1971; 50: 827-837.

21 Maggiorini M, Melot C, Pierre S, et al. High-altitude pulmonary edema is initially caused by an increase in capillary pressure. Circulation 2001; 103: 2078-2083.

22 Berger MM, Hesse C, Dehnert C, et al. Hypoxia impairs systemic endothelial function in individuals prone to high-altitude pulmonary edema. Am J Respir Crit Care Med 2005; 172: 763-767.

23 Dehnert C, Grunig E, Mereles D, von Lennep N, Bartsch P. Identification of individuals susceptible to high-altitude pulmonary oedema at low altitude. Eur Respir J 2005; 25: 545-551.

24 Naeije R. Pulmonary circulation at high altitude. Respiration 1997; 64: 429-434.

25 Tenney SM, Rahn H, Stroud RC, Mithoefer JC. Adoption to high altitude: changes in lung volumes during the first seven days at Mt. Evans, Colorado. J Appl Physiol 1953; 5: 607-613.

26 Rahn H, Hammond D. Vital capacity at reduced barometric pressure. J Appl Physiol 1952; 4: 715-724.

27 Mason NP, Barry PW, Pollard AJ, et al. Serial changes in spirometry during an ascent to $5,300 \mathrm{~m}$ in the Nepalese Himalayas. High Alt Med Biol 2000; 1: 185-195.

28 Welsh CH, Wagner PD, Reeves JT, et al. Operation Everest. II: Spirometric and radiographic changes in acclimatized humans at simulated high altitudes. Am Rev Respir Dis 1993; 147: 1239-1244.

29 Deboeck G, Moraine JJ, Naeije R. Respiratory muscle strength may explain hypoxia-induced decrease in vital capacity. Med Sci Sports Exerc 2005; 37: 754-758.

30 Mansell A, Powles A, Sutton J. Changes in pulmonary PV characteristics of human subjects at an altitude of 5,366 m. J Appl Physiol 1980; 49: 79-83.

31 Gautier H, Peslin R, Grassino A, et al. Mechanical properties of the lungs during acclimatization to altitude. J Appl Physiol 1982; 52: 1407-1415.

32 Pollard AJ, Mason NP, Barry PW, et al. Effect of altitude on spirometric parameters and the performance of peak flow meters. Thorax 1996; 51: 175-178.
33 Raymond L, Severinghaus JW. Static pulmonary compliance of man during altitude hypoxia. J Appl Physiol 1971; 31: 785-787.

34 Forte VA Jr, Leith DE, Muza SR, Fulco CS, Cymerman A. Ventilatory capacities at sea level and high altitude. Aviat Space Environ Med 1997; 68: 488-493.

35 Hackett PH, Roach RC. High-altitude illness. N Engl J Med 2001; 345: 107-114.

36 Bartsch P, Mairbaurl H, Maggiorini M, Swenson ER. Physiological aspects of high-altitude pulmonary edema. J Appl Physiol 2005; 98: 1101-1110.

37 Basnyat B, Murdoch DR. High-altitude illness. Lancet 2003; 361: 1967-1974.

38 Leon-Velarde F, Maggiorini M, Reeves JT, et al. Consensus statement on chronic and subacute high altitude diseases. High Alt Med Biol 2005; 6: 147-157.

39 Leon-Velarde F, Reeves JT. International consensus group on chronic mountain sickness. Adv Exp Med Biol 1999; 474: 351-353.

40 Honigman B, Theis MK, Koziol-McLain J, et al. Acute mountain sickness in a general tourist population at moderate altitudes. Ann Intern Med 1993; 118: 587-592.

41 Hackett PH, Rennie D. The incidence, importance, and prophylaxis of acute mountain sickness. Lancet 1976; 2: 1149-1155.

42 Roach RC, Bartsch P, Hackett PH, Oelz O. The Lake Louise Acute Mountain Sickness Scoring System. In: Sutton JR, Coates G, Houston CS, eds. Hypoxia and Molecular Medicine: Proceedings of the 8th International Hypoxia Symposium, Lake Louise, Alberta, Canada. Burlington, Queen City Printers, 1993; pp. 272-274.

43 Larson EB, Roach RC, Schoene RB, Hornbein TF. Acute mountain sickness and acetazolamide. Clinical efficacy and effect on ventilation. JAMA 1982; 248: 328-332.

44 Hackett PH, Roach RC, Wood RA, et al. Dexamethasone for prevention and treatment of acute mountain sickness. Aviat Space Environ Med 1988; 59: 950-954.

45 Basnyat B, Gertsch JH, Holck PS, et al. Acetazolamide $125 \mathrm{mg} \mathrm{BD}$ is not significantly different from $375 \mathrm{mg}$ BD in the prevention of acute mountain sickness: the prophylactic acetazolamide dosage comparison for efficacy (PACE) trial. High Alt Med Biol 2006; 7: 17-27.

46 Grissom CK, Roach RC, Sarnquist FH, Hackett PH. Acetazolamide in the treatment of acute mountain sickness: clinical efficacy and effect on gas exchange. Ann Intern Med 1992; 116: 461-465.

47 Bartsch P, Maggiorini M, Mairbaurl H, Vock P, Swenson ER. Pulmonary extravascular fluid accumulation in climbers. Lancet 2002; 360: 571.

48 Singh I, Kapila CC, Khanna PK, Nanda RB, Rao BD. High-altitude pulmonary oedema. Lancet 1965; 191: 229-234.

49 Hultgren HN, Grover RF, Hartley LH. Abnormal circulatory responses to high altitude in subjects with a previous history of high-altitude pulmonary edema. Circulation 1971; 44: 759-770.

50 Hultgren HN, Lopez CE, Lundberg E, Miller H. Physiologic studies of pulmonary edema at high altitude. Circulation 1964; 29: 393-408.

51 Grunig E, Mereles D, Hildebrandt W, et al. Stress Doppler echocardiography for identification of susceptibility to 
high altitude pulmonary edema. I Am Coll Cardiol 2000; 35: 980-987.

52 Oelz O, Maggiorini M, Ritter M, et al. Nifedipine for high altitude pulmonary oedema. Lancet 1989; 2: 1241-1244.

53 Sartori C, Allemann Y, Duplain H, et al. Salmeterol for the prevention of high-altitude pulmonary edema. $N$ Engl J Med 2002; 346: 1631-1636.

54 Anand IS, Malhotra RM, Chandrashekhar Y, et al. Adult subacute mountain sickness--a syndrome of congestive heart failure in man at very high altitude. Lancet 1990; 335: 561-565.

55 Maggiorini M, Leon-Velarde F. High-altitude pulmonary hypertension: a pathophysiological entity to different diseases. Eur Respir J 2003; 22: 1019-1025.

56 Monge CC, Whittembury J. Chronic mountain sickness. Johns Hopkins Med J 1976; 139: Suppl., 87-89.

57 Cruz JC, Diaz C, Marticorena E, Hilario V. Phlebotomy improves pulmonary gas exchange in chronic mountain polycythemia. Respiration 1979; 38: 305-313.

58 Winslow RM, Monge CC, Brown EG, et al. Effects of hemodilution on $\mathrm{O}_{2}$ transport in high-altitude polycythemia. J Appl Physiol 1985; 59: 1495-1502.

59 Manier G, Guenard H, Castaing Y, Varene N, Vargas E. Pulmonary gas exchange in Andean natives with excessive polycythemia--effect of hemodilution. I Appl Physiol 1988; 65: 2107-2117.

60 Richalet JP, Rivera M, Bouchet P, et al. Acetazolamide: a treatment for chronic mountain sickness. Am J Respir Crit Care Med 2005; 172: 1427-1433.

61 Kryger M, McCullough RE, Collins D, Scoggin CH, Weil JV, Grover RF. Treatment of excessive polycythemia of high altitude with respiratory stimulant drugs. Am Rev Respir Dis 1978; 117: 455-464.

62 Pei SX, Chen XJ, Si Ren BZ, et al. Chronic mountain sickness in Tibet. Q J Med 1989; 71: 555-574.

63 Ge RL, Helun G. Current concept of chronic mountain sickness: pulmonary hypertension-related high altitude heart disease. Wilderness Environ Med 2001; 12: 190-194.

64 Aldashev AA, Sarybaev AS, Sydykov AS, et al. Characterization of high-altitude pulmonary hypertension in the Kyrgyz: association with angiotensin-converting enzyme genotype. Am J Respir Crit Care Med 2002; 166: 1396-1402.

65 Cote TR, Stroup DF, Dwyer DM, Horan JM, Peterson DE. Chronic obstructive pulmonary disease mortality. A role for altitude. Chest 1993; 103: 1194-1197.

66 Moore LG, Rohr AL, Maisenbach JK, Reeves JT. Emphysema mortality is increased in Colorado residents at high altitude. Am Rev Respir Dis 1982; 126: 225-228.

67 Renzetti AD Jr, McClement JH, Litt BD. The Veterans Administration cooperative study of pulmonary function. 3. Mortality in relation to respiratory function in chronic obstructive pulmonary disease. Am J Med 1966; 41: 115-129.

68 Sauer HI. Geographic patterns in the risk of dying and associated factors ages 35-74 years: United States, 1968 72. Vital Health Stat 3 1980; 18: 1-120.

69 Coultas DB, Samet JM, Wiggins CL. Altitude and mortality from chronic obstructive lung disease in New Mexico. Arch Environ Health 1984; 39: 355-359.
70 Graham WG, Houston CS. Short-term adaptation to moderate altitude. Patients with chronic obstructive pulmonary disease. JAMA 1978; 240: 1491-1494.

71 Dillard TA, Berg BW, Rajagopal KR, Dooley JW, Mehm WJ. Hypoxemia during air travel in patients with chronic obstructive pulmonary disease. Ann Intern Med 1989; 111: 362-367.

72 Christensen CC, Ryg M, Refvem OK, Skjonsberg OH. Development of severe hypoxaemia in chronic obstructive pulmonary disease patients at $2,438 \mathrm{~m}(8,000 \mathrm{ft})$ altitude. Eur Respir J 2000; 15: 635-639.

73 Berg BW, Dillard TA, Rajagopal KR, Mehm WJ. Oxygen supplementation during air travel in patients with chronic obstructive lung disease. Chest 1992; 101: 638-641.

74 Seccombe LM, Kelly PT, Wong CK, Rogers PG, Lim S, Peters MJ. Effect of simulated commercial flight on oxygenation in patients with interstitial lung disease and chronic obstructive pulmonary disease. Thorax 2004; 59: 966-970.

75 Standards for the diagnosis and care of patients with chronic obstructive pulmonary disease. American Thoracic Society. Am J Respir Crit Care Med 1995; 152: S112-S113.

76 Medical guidelines for air travel. Aerospace Medical Association, Air Transport Medicine Committee, Alexandria, VA. Aviat Space Environ Med 1996; 67: Suppl. 10, B1-B16.

77 Gong H Jr, Tashkin DP, Lee EY, Simmons MS. Hypoxiaaltitude simulation test. Evaluation of patients with chronic airway obstruction. Am Rev Respir Dis 1984; 130: 980-986.

78 Cottrell JJ. Altitude exposures during aircraft flight. Flying higher. Chest 1988; 93: 81-84.

79 Dillard TA, Rosenberg AP, Berg BW. Hypoxemia during altitude exposure. A meta-analysis of chronic obstructive pulmonary disease. Chest 1993; 103: 422-425.

80 Akero A, Christensen CC, Edvardsen A, Skjonsberg OH. Hypoxaemia in chronic obstructive pulmonary disease patients during a commercial flight. Eur Respir J 2005; 25: 725-730.

81 Dillard TA, Beninati WA, Berg BW. Air travel in patients with chronic obstructive pulmonary disease. Arch Intern Med 1991; 151: 1793-1795.

82 Schwartz JS, Bencowitz HZ, Moser KM. Air travel hypoxemia with chronic obstructive pulmonary disease. Ann Intern Med 1984; 100: 473-477.

83 Finkelstein S, Tomashefski JF, Shillito FH. Pulmonary mechanics at altitude in normal and obstructive lung disease patients. Aerosp Med 1965; 36: 880-884.

84 Dillard TA, Rajagopal KR, Slivka WA, Berg BW, Mehm WJ, Lawless NP. Lung function during moderate hypobaric hypoxia in normal subjects and patients with chronic obstructive pulmonary disease. Aviat Space Environ Med 1998; 69: 979-985.

85 Astin TW, Penman RW. Airway obstruction due to hypoxemia in patients with chronic lung disease. $A m$ Rev Respir Dis 1967; 95: 567-575.

86 Libby DM, Briscoe WA, King TK. Relief of hypoxiarelated bronchoconstriction by breathing 30 per cent oxygen. Am Rev Respir Dis 1981; 123: 171-175. 
87 Koskela HO, Koskela AK, Tukiaineu HO. Bronchoconstriction due to cold weather in COPD. The roles of direct airway effects and cutaneous reflex mechanisms. Chest 1996; 110: 632-636.

88 Koskela H, Pihlajamaki J, Pekkarinen H, Tukiainen H. Effect of cold air on exercise capacity in COPD: increase or decrease? Chest 1998; 113: 1560-1565.

89 Spence DP, Graham DR, Ahmed J, Rees K, Pearson MG, Calverley PM. Does cold air affect exercise capacity and dyspnea in stable chronic obstructive pulmonary disease? Chest 1993; 103: 693-696.

90 Parker GW, Stonehill RB. Further considerations of the roentgenologic evaluation of flying personnel at simulated altitude. Aeromed Acta 1961; 32: 501-504.

91 Tomashefski JF, Feeley DR, Shillito FH. Effects of altitude on emphysematous blebs and bullae. Aerosp Med 1966; 37: 1158-1162.

92 Yanda RL, Herschensohn HL. Changes in lung volumes of emphysema patients upon short exposures to simulated altitude of 18,000 feet. Aerosp Med 1964; 35: 1201-1203.

93 Barbera JA, Peinado VI, Santos S. Pulmonary hypertension in chronic obstructive pulmonary disease. Eur Respir J 2003; 21: 892-905.

94 Naeije R, Barbera JA. Pulmonary hypertension associated with COPD. Crit Care 2001; 5: 286-289.

95 Bedu M, Giraldo H, Janicot H, Fellmann N, Coudert J. Interaction between cold and hypoxia on pulmonary circulation in COPD. Am J Respir Crit Care Med 1996; 153: 1242-1247.

96 McKerrow CB, Otis AB. Oxygen cost of hyperventilation. J Appl Physiol 1956; 9: 375-379.

97 Shindoh C, Hida W, Kikuchi Y, et al. Oxygen consumption of respiratory muscles in patients with COPD. Chest 1994; 105: 790-797.

98 Mador MJ, Kufel TJ, Pineda LA, Sharma GK. Diaphragmatic fatigue and high-intensity exercise in patients with chronic obstructive pulmonary disease. Am J Respir Crit Care Med 2000; 161: 118-123.

99 Lewis MI, Belman MJ, Monn SA, Elashoff JD, Koerner SK. The relationship between oxygen consumption and work rate in patients with airflow obstruction. Chest 1994; 106: 366-372.

100 Burghuber OC. Nifedipine attenuates acute hypoxic pulmonary vasoconstriction in patients with chronic obstructive pulmonary disease. Respiration 1987; 52: 86-93.

101 Kennedy TP, Michael JR, Huang CK, et al. Nifedipine inhibits hypoxic pulmonary vasoconstriction during rest and exercise in patients with chronic obstructive pulmonary disease. A controlled double-blind study. Am Rev Respir Dis 1984; 129: 544-551.

102 Cheatham ML, Safcsak K. Air travel following traumatic pneumothorax: when is it safe? Am Surg 1999; 65: 1160-1164.

103 Storm van Leeuwen W, Varekamp H, Bien L. Asthma bronchiale und klima. [Bronchial asthma and climate.] Kliniche Wochenschrift 1924; 3: 520-523.

104 Vargas MH, Sienra-Monge JJ, Diaz-Mejia G, DeLeonGonzalez M. Asthma and geographical altitude: an inverse relationship in Mexico. J Asthma 1999; 36: 511-517.

105 Gourgoulianis KI, Brelas N, Hatziparasides G, Papayianni M, Molyvdas PA. The influence of altitude in bronchial asthma. Arch Med Res 2001; 32: 429-431.

106 Golan Y, Onn A, Villa Y, et al. Asthma in adventure travelers: a prospective study evaluating the occurrence and risk factors for acute exacerbations. Arch Intern Med 2002; 162: 2421-2426.

107 Simon HU, Grotzer M, Nikolaizik WH, Blaser K, Schoni MH. High altitude climate therapy reduces peripheral blood T lymphocyte activation, eosinophilia, and bronchial obstruction in children with house-dust mite allergic asthma. Pediatr Pulmonol 1994; 17: 304-311.

108 Peroni DG, Boner AL, Vallone G, Antolini I, Warner JO. Effective allergen avoidance at high altitude reduces allergen-induced bronchial hyperresponsiveness. Am J Respir Crit Care Med 1994; 149: 1442-1446.

109 Boner AL, Peroni DG, Piacentini GL, Venge P. Influence of allergen avoidance at high altitude on serum markers of eosinophil activation in children with allergic asthma. Clin Exp Allergy 1993; 23: 1021-1026.

110 Grootendorst DC, Dahlen SE, Van Den Bos JW, et al. Benefits of high altitude allergen avoidance in atopic adolescents with moderate to severe asthma, over and above treatment with high dose inhaled steroids. Clin Exp Allergy 2001; 31: 400-408.

111 Charpin D, Kleisbauer JP, Lanteaume A, et al. Asthma and allergy to house-dust mites in populations living in high altitudes. Chest 1988; 93: 758-761.

112 Charpin D, Birnbaum J, Haddi E, et al. Altitude and allergy to house-dust mites. A paradigm of the influence of environmental exposure on allergic sensitization. Am Rev Respir Dis 1991; 143: 983-986.

113 van Velzen E, van den Bos JW, Benckhuijsen JA, van Essel T, de Bruijn R, Aalbers R. Effect of allergen avoidance at high altitude on direct and indirect bronchial hyperresponsiveness and markers of inflammation in children with allergic asthma. Thorax 1996; 51: 582-584.

114 Valletta EA, Comis A, Del Col G, Spezia E, Boner AL. Peak expiratory flow variation and bronchial hyperresponsiveness in asthmatic children during periods of antigen avoidance and reexposure. Allergy 1995; 50: 366-369.

115 Peroni DG, Piacentini GL, Costella S, et al. Mite avoidance can reduce air trapping and airway inflammation in allergic asthmatic children. Clin Exp Allergy 2002; 32: 850-855.

116 Denjean A, Roux C, Herve $\mathrm{P}$, et al. Mild isocapnic hypoxia enhances the bronchial response to methacholine in asthmatic subjects. Am Rev Respir Dis 1988; 138: 789-793.

117 Dagg KD, Thomson LJ, Clayton RA, Ramsay SG, Thomson NC. Effect of acute alterations in inspired oxygen tension on methacholine induced bronchoconstriction in patients with asthma. Thorax 1997; 52: 453-457.

118 Alberts WM, Colice GC, Hammond MD, Goldman AL. Effect of mild hypoxemia on bronchial responsiveness. Ann Allergy 1990; 65: 189-193. 
119 Saito H, Nishimura M, Shinano H, Sato F, Miyamoto K, Kawakami Y. Effect of mild hypoxia on airway responsiveness to methacholine in subjects with airway hyperresponsiveness. Chest 1999; 116: 1653-1658.

120 Tam EK, Geffroy BA, Myers DJ, Seltzer J, Sheppard D, Boushey HA. Effect of eucapnic hypoxia on bronchomotor tone and on the bronchomotor response to dry air in asthmatic subjects. Am Rev Respir Dis 1985; 132: 690-693.

121 Eckert DJ, Catcheside PG, Smith JH, Frith PA, McEvoy RD. Hypoxia suppresses symptom perception in asthma. Am J Respir Crit Care Med 2004; 169: 1224-1230.

122 Dagg KD, Clayton RA, Thomson LJ, Chalmers GW, McGrath JC, Thomson NC. The effect of acute alteration in oxygen tension on the bronchodilator response to salbutamol in vitro and in vivo in man. Pulm Pharmacol Ther 2001; 14: 99-105.

123 Newhouse MT, Becklake MR, Macklem PT, McGregor M. Effect of alterations in end-tidal $\mathrm{CO}_{2}$ tension on flow resistance. J Appl Physiol 1964; 19: 745-749.

124 van den Elshout FJ, van Herwaarden CL, Folgering HT. Effects of hypercapnia and hypocapnia on respiratory resistance in normal and asthmatic subjects. Thorax 1991; 46: 28-32.

125 Nielsen TM, Pedersen OF. The effect of $\mathrm{CO}_{2}$ on peripheral airways. Acta Physiol Scand 1976; 98: 192-199.

126 Cutillo A, Omboni E, Perondi R, Tana F. Effect of hypocapnia on pulmonary mechanics in normal subjects and in patients with chronic obstructive lung disease. Am Rev Respir Dis 1974; 110: 25-33.

127 Nielsen KG, Bisgaard H. Hyperventilation with cold versus dry air in 2- to 5-year-old children with asthma. Am J Respir Crit Care Med 2005; 171: 238-241.

128 Nair N, Hopp RJ, Alper BI, Bewtra AK, Townley RG. Correlation of methacholine-induced non-specific bronchial reactivity and cold air hyperventilation challenge. Ann Allergy 1986; 56: 226-228.

129 Larsson K, Ohlsen P, Larsson L, Malmberg P, Rydstrom PO, Ulriksen $\mathrm{H}$. High prevalence of asthma in cross country skiers. BMJ 1993; 307: 1326-1329.

130 Pohjantahti H, Laitinen J, Parkkari J. Exercise-induced bronchospasm among healthy elite cross country skiers and non-athletic students. Scand J Med Sci Sports 2005; 15: 324-328.

131 Durand F, Kippelen P, Ceugniet F, et al. Undiagnosed exercise-induced bronchoconstriction in ski-mountaineers. Int J Sports Med 2005; 26: 233-237.

132 Kaminsky DA, Irvin CG, Gurka DA, et al. Peripheral airways responsiveness to cool, dry air in normal and asthmatic individuals. Am J Respir Crit Care Med 1995; 152: 1784-1790.

133 Dosman JA, Hodgson WC, Cockcroft DW. Effect of cold air on the bronchial response to inhaled histamine in patients with asthma. Am Rev Respir Dis 1991; 144: 45-50.

134 Ahmed T, Danta I. Effect of cold air exposure and exercise on nonspecific bronchial reactivity. Chest 1988; 93: $1132-1136$.

135 Skowronski ME, Ciufo R, Nelson JA, McFadden ER Jr. Effects of skin cooling on airway reactivity in asthma. Clin Sci (Lond) 1998; 94: 525-529.

136 Zeitoun M, Wilk B, Matsuzaka A, Knopfli BH, Wilson BA, Bar-Or O. Facial cooling enhances exercise-induced bronchoconstriction in asthmatic children. Med Sci Sports Exerc 2004; 36: 767-771.

137 Tessier P, Cartier A, Ghezzo H, Martin RR, Malo JL. Bronchoconstriction due to exercise combined with cold air inhalation does not generally influence bronchial responsiveness to inhaled histamine in asthmatic subjects. Eur Respir J 1988; 1: 133-138.

138 Juniper EF, Latimer KM, Morris MM, Roberts RS, Hargreave FE. Airway responses to hyperventilation of cold dry air: duration of protection by cromolyn sodium. J Allergy Clin Immunol 1986; 78: 387-391.

139 O'Donnell WJ, Rosenberg M, Niven RW, Drazen JM, Israel E. Acetazolamide and furosemide attenuate asthma induced by hyperventilation of cold, dry air. Am Rev Respir Dis 1992; 146: 1518-1523.

140 Henderson AF, Heaton RW, Costello JF. Effect of nifedipine on bronchoconstriction induced by inhalation of cold air. Thorax 1983; 38: 512-515.

141 Kass JE, Terregino CA. The effect of heliox in acute severe asthma: a randomized controlled trial. Chest 1999; 116: 296-300.

142 Bag R, Bandi V, Fromm RE Jr, Guntupalli KK. The effect of heliox-driven bronchodilator aerosol therapy on pulmonary function tests in patients with asthma. $J$ Asthma 2002; 39: 659-665.

143 Kress JP, Noth I, Gehlbach BK, et al. The utility of albuterol nebulized with heliox during acute asthma exacerbations. Am J Respir Crit Care Med 2002; 165: 1317-1321.

144 Ho AM, Lee A, Karmakar MK, Dion PW, Chung DC, Contardi LH. Heliox versus air-oxygen mixtures for the treatment of patients with acute asthma: a systematic overview. Chest 2003; 123: 882-890.

145 Rodrigo G, Pollack C, Rodrigo C, Rowe BH. Heliox for nonintubated acute asthma patients. Cochrane Database Syst Rev 2003; 4: CD002884.

146 Louie D, Pare PD. Physiological changes at altitude in nonasthmatic and asthmatic subjects. Can Respir J 2004; 11: 197-199.

147 Cogo A, Basnyat B, Legnani D, Allegra L. Bronchial asthma and airway hyperresponsiveness at high altitude. Respiration 1997; 64: 444-449.

148 Allegra L, Cogo A, Legnani D, Diano PL, Fasano V, Negretto GG. High altitude exposure reduces bronchial responsiveness to hypo-osmolar aerosol in lowland asthmatics. Eur Respir J 1995; 8: 1842-1846.

149 Pedersen OF, Miller MR, Sigsgaard T, Tidley M, Harding RM. Portable peak flow meters: physical characteristics, influence of temperature, altitude, and humidity. Eur Respir J 1994; 7: 991-997.

150 Thomas PS, Harding RM, Milledge JS. Peak expiratory flow at altitude. Thorax 1990; 45: 620-622.

151 Fischer R, Lang SM, Bruckner K, et al. Lung function in adults with cystic fibrosis at altitude: impact on air travel. Eur Respir J 2005; 25: 718-724.

152 Thews O, Fleck B, Kamin WE, Rose DM. Respiratory function and blood gas variables in cystic fibrosis patients during reduced environmental pressure. Eur J Appl Physiol 2004; 92: 493-497.

153 Rose DM, Fleck B, Thews O, Kamin WE. Blood gasanalyses in patients with cystic fibrosis to estimate 
hypoxemia during exposure to high altitudes in a hypobaric-chamber. Eur J Med Res 2000; 5: 9-12.

154 Ryujin DT, Mannebach SC, Samuelson WM, Marshall BC. Oxygen saturation in adult cystic fibrosis patients during exercise at high altitude. Pediatr Pulmonol 2001; 32: 437-441.

155 Kamin W, Fleck B, Rose DM, Thews O, Thielen W. Predicting hypoxia in cystic fibrosis patients during exposure to high altitudes. J Cyst Fibros 2006; 5: 223-228.

156 Speechly-Dick ME, Rimmer SJ, Hodson ME. Exacerbations of cystic fibrosis after holidays at high altitude - a cautionary tale. Respir Med 1992; 86: 55-56.

157 Oades PJ, Buchdahl RM, Bush A. Prediction of hypoxaemia at high altitude in children with cystic fibrosis. BMJ 1994; 308: 15-18.

158 Swenson ER, Maggiorini M, Mongovin S, et al. Pathogenesis of high-altitude pulmonary edema: inflammation is not an etiologic factor. JAMA 2002; 287: 2228-2235.

159 Hackett PH, Creagh CE, Grover RF, et al. High-altitude pulmonary edema in persons without the right pulmonary artery. N Engl J Med 1980; 302: 1070-1073.

160 Rios B, Driscoll DJ, McNamara DG. High-altitude pulmonary edema with absent right pulmonary artery. Pediatrics 1985; 75: 314-317.

161 Torrington KG. Recurrent high-altitude illness associated with right pulmonary artery occlusion from granulomatous mediastinitis. Chest 1989; 96: 1422-1424.

162 Nakagawa S, Kubo K, Koizumi T, Kobayashi T, Sekiguchi M. High-altitude pulmonary edema with pulmonary thromboembolism. Chest 1993; 103: 948-950.

163 Naeije R, De Backer D, Vachiery JL, De Vuyst P. Highaltitude pulmonary edema with primary pulmonary hypertension. Chest 1996; 110: 286-289.

164 Durmowicz AG. Pulmonary edema in 6 children with Down syndrome during travel to moderate altitudes. Pediatrics 2001; 108: 443-447.

165 Das BB, Wolfe RR, Chan KC, Larsen GL, Reeves JT, Ivy D. High-altitude pulmonary edema in children with underlying cardiopulmonary disorders and pulmonary hypertension living at altitude. Arch Pediatr Adolesc Med 2004; 158: 1170-1176.

$166 \mathrm{Wu}$ T. A Tibetan with chronic mountain sickness followed by high altitude pulmonary edema on reentry. High Alt Med Biol 2004; 5: 190-194.

167 Gabry AL, Ledoux X, Mozziconacci M, Martin C. Highaltitude pulmonary edema at moderate altitude $(<$ 2,400 m; 7,870 feet): a series of 52 patients. Chest 2003; 123: 49-53.

168 Oelz O, Maggiorini M, Ritter M, et al. Prevention and treatment of high altitude pulmonary edema by a calcium channel blocker. Int J Sports Med 1992; 13: Suppl. 1, S65-68.

169 Zhao L, Mason NA, Morrell NW, et al. Sildenafil inhibits hypoxia-induced pulmonary hypertension. Circulation 2001; 104: 424-428.

170 Maggiorini M, Brunner-La Rocca H, Peth S, et al. Both tadalafil and dexamethasone may reduce the incidence of high altitude pulmonary edema: a randomized trial. Ann Intern Med 2006; 145: 497-506.
171 Anand AC, Jha SK, Saha A, Sharma V, Adya CM. Thrombosis as a complication of extended stay at high altitude. Natl Med J India 2001; 14: 197-201.

172 Sharma SC. Platelet count in temporary residents of high altitude. J Appl Physiol 1980; 49: 1047-1048.

173 Chatterji JC, Ohri VC, Das BK, et al. Platelet count, platelet aggregation and fibrinogen levels following acute induction to high altitude (3200 and 3771 metres). Thromb Res 1982; 26: 177-182.

174 Gray GW, Bryan AC, Freedman MH, et al. Effect of altitude exposure on platelets. J Appl Physiol 1975; 39: 648-652.

175 Lehmann T, Mairbaurl H, Pleisch B, Maggiorini M, Bartsch P, Reinhart WH. Platelet count and function at high altitude and in high-altitude pulmonary edema. J Appl Physiol 2006; 100: 690-694.

176 Maher JT, Levine PH, Cymerman A. Human coagulation abnormalities during acute exposure to hypobaric hypoxia. J Appl Physiol 1976; 41: 702-707.

177 Doughty HA, Beardmore C. Bleeding time at altitude. J R Soc Med 1994; 87: 317-319.

178 Bartsch P, Haeberli A, Franciolli M, Kruithof EK, Straub PW. Coagulation and fibrinolysis in acute mountain sickness and beginning pulmonary edema. J Appl Physiol 1989; 66: 2136-2144.

179 O'Brodovich HM, Andrew M, Gray GW, Coates G. Hypoxia alters blood coagulation during acute decompression in humans. J Appl Physiol 1984; 56: 666-670.

180 Bartsch P, Haeberli A, Hauser K, Gubser A, Straub PW. Fibrinogenolysis in the absence of fibrin formation in severe hypobaric hypoxia. Aviat Space Environ Med 1988; 59: 428-432.

181 Mannucci PM, Gringeri A, Peyvandi F, Di Paolantonio T, Mariani G. Short-term exposure to high altitude causes coagulation activation and inhibits fibrinolysis. Thromb Haemost 2002; 87: 342-343.

182 Bendz B, Rostrup M, Sevre K, Andersen TO, Sandset PM. Association between acute hypobaric hypoxia and activation of coagulation in human beings. Lancet 2000; 356: 1657-1658.

183 Bartsch P, Straub PW, Haeberli A. Hypobaric hypoxia. Lancet 2001; 357: 955-956.

184 Schreijer AJ, Cannegieter SC, Meijers JC, Middeldorp S, Buller HR, Rosendaal FR. Activation of coagulation system during air travel: a crossover study. Lancet 2006; 367: 832-838.

185 Shlim DR, Papenfus K. Pulmonary embolism presenting as high-altitude pulmonary edema. Wilderness Environ Med 1995; 6: 220-224.

186 Boulos P, Kouroukis C, Blake G. Superior sagittal sinus thrombosis occurring at high altitude associated with protein C deficiency. Acta Haematol 1999; 102: 104-106.

187 Saito S, Tanaka SK. A case of cerebral sinus thrombosis developed during a high-altitude expedition to Gasherbrum I. Wilderness Environ Med 2003; 14: 226-230.

188 Torgovicky R, Azaria B, Grossman A, Eliyahu U, Goldstein L. Sinus vein thrombosis following exposure to simulated high altitude. Aviat Space Environ Med 2005; 76: 144-146.

189 Ashraf HM, Javed A, Ashraf S. Pulmonary embolism at high altitude and hyperhomocysteinemia. I Coll Physicians Surg Pak 2006; 16: 71-73. 
190 Heffner JE, Sahn SA. High-altitude pulmonary infarction. Arch Intern Med 1981; 141: 1721.

191 Van Patot MC, Hill AE, Dingmann C, et al. Risk of impaired coagulation in warfarin patients ascending to altitude (>2400 m). High Alt Med Biol 2006; 7: 39-46.

192 Alpert MA. Obesity cardiomyopathy: pathophysiology and evolution of the clinical syndrome. Am J Med Sci 2001; 321: 225-236.

193 Kessler R, Chaouat A, Schinkewitch P, et al. The obesityhypoventilation syndrome revisited: a prospective study of 34 consecutive cases. Chest 2001; 120: 369-376.

194 Toff NJ. Hazards of air travel for the obese: Miss Pickwick and the Boeing 747. J $R$ Coll Physicians Lond 1993; 27: 375-376.

195 Ri-Li G, Chase PJ, Witkowski S, et al. Obesity: associations with acute mountain sickness. Ann Intern Med 2003; 139: 253-257.

196 Eichenberger U, Weiss E, Riemann D, Oelz O, Bartsch P. Nocturnal periodic breathing and the development of acute high altitude illness. Am J Respir Crit Care Med 1996; 154: 1748-1754.

197 Burgess KR, Johnson P, Edwards N, Cooper J. Acute mountain sickness is associated with sleep desaturation at high altitude. Respirology 2004; 9: 485-492.

198 Erba P, Anastasi S, Senn O, Maggiorirni M, Bloch KE. Acute mountain sickness is related to nocturnal hypoxemia but not to hypoventilation. Eur Respir J 2004; 24: 303-308.

199 Gertsch JH, Basnyat B, Johnson EW, Onopa J, Holck PS. Randomised, double blind, placebo controlled comparison of ginkgo biloba and acetazolamide for prevention of acute mountain sickness among Himalayan trekkers: the prevention of high altitude illness trial (PHAIT). BMJ 2004; 328: 797.

200 Murdoch DR. Symptoms of infection and altitude illness among hikers in the Mount Everest region of Nepal. Aviat Space Environ Med 1995; 66: 148-151.

201 Lupi-Herrera E, Seoane M, Sandoval J, Casanova JM, Bialostozky D. Behavior of the pulmonary circulation in the grossly obese patient. Pathogenesis of pulmonary arterial hypertension at an altitude of 2,240 meters. Chest 1980; 78: 553-558.

202 Valencia-Flores M, Rebollar V, Santiago V, et al. Prevalence of pulmonary hypertension and its association with respiratory disturbances in obese patients living at moderately high altitude. Int J Obes Relat Metab Disord 2004; 28: 1174-1180.

203 Swenson ER. Carbonic anhydrase inhibitors and ventilation: a complex interplay of stimulation and suppression. Eur Respir J 1998; 12: 1242-1247.

204 Lyons HA, Huang CT. Therapeutic use of progesterone in alveolar hypoventilation associated with obesity. Am J Med 1968; 44: 881-888.

205 Sutton FD Jr, Zwillich CW, Creagh CE, Pierson DJ, Weil JV. Progesterone for outpatient treatment of Pickwickian syndrome. Ann Intern Med 1975; 83: 476-479.

206 Strohl KP, Hensley MJ, Saunders NA, Scharf SM, Brown R, Ingram RH Jr. Progesterone administration and progressive sleep apneas. JAMA 1981; 245: $1230-1232$.
207 Orr WC, Imes NK, Martin RJ. Progesterone therapy in obese patients with sleep apnea. Arch Intern Med 1979; 139: 109-111.

208 Fromm RE Jr, Varon J, Lechin AE, Hirshkowitz M. CPAP machine performance and altitude. Chest 1995; 108: 1577-1580.

209 Burgess KR, Johnson PL, Edwards N. Central and obstructive sleep apnoea during ascent to high altitude. Respirology 2004; 9: 222-229.

210 Netzer NC, Strohl KP. Sleep and breathing in recreational climbers at an altitude of 4200 and 6400 meters: observational study of sleep and patterning of respiration during sleep in a group of recreational climbers. Sleep Breath 1999; 3: 75-82.

211 Chaouat A, Weitzenblum E, Krieger J, Oswald M, Kessler R. Pulmonary hemodynamics in the obstructive sleep apnea syndrome. Results in 220 consecutive patients. Chest 1996; 109: 380-386.

212 Laks L, Lehrhaft B, Grunstein RR, Sullivan CE. Pulmonary hypertension in obstructive sleep apnoea. Eur Respir J 1995; 8: 537-541.

213 Weitzenblum E, Krieger J, Apprill M, et al. Daytime pulmonary hypertension in patients with obstructive sleep apnea syndrome. Am Rev Respir Dis 1988; 138: 345-349.

214 Kessler R, Chaouat A, Weitzenblum E, et al. Pulmonary hypertension in the obstructive sleep apnoea syndrome: prevalence, causes and therapeutic consequences. Eur Respir J 1996; 9: 787-794.

215 Lahiri S, Barnard P. Role of arterial chemoreflex in breathing during sleep at high altitude. Prog Clin Biol Res 1983; 136: 75-85.

216 Lahiri S, Maret K, Sherpa MG. Dependence of high altitude sleep apnea on ventilatory sensitivity to hypoxia. Respir Physiol 1983; 52: 281-301.

217 Reite M, Jackson D, Cahoon RL, Weil JV. Sleep physiology at high altitude. Electroencephalogr Clin Neurophysiol 1975; 38: 463-471.

218 White DP, Zwillich CW, Pickett CK, Douglas NJ, Findley LJ, Weil JV. Central sleep apnea. Improvement with acetazolamide therapy. Arch Intern Med 1982; 142: 1816-1819.

219 Fischer R, Lang SM, Leitl M, Thiere M, Steiner U, Huber RM. Theophylline and acetazolamide reduce sleep-disordered breathing at high altitude. Eur Respir J 2004; 23: 47-52.

220 Hackett PH, Roach RC, Harrison GL, Schoene RB, Mills WJ Jr. Respiratory stimulants and sleep periodic breathing at high altitude. Almitrine versus acetazolamide. Am Rev Respir Dis 1987; 135: 896-898.

221 Javaheri S. Acetazolamide improves central sleep apnea in heart failure: a double-blind, prospective study. $A m \mathrm{~J}$ Respir Crit Care Med 2006; 173: 234-237.

222 Javaheri S, Parker TJ, Liming JD, et al. Sleep apnea in 81 ambulatory male patients with stable heart failure. Types and their prevalences, consequences and presentations. Circulation 1998; 97: 2154-2159.

223 Bradley TD, Floras JS. Sleep apnea and heart failure. Part II: central sleep apnea. Circulation 2003; 107: 1822-1826. 
224 Vizek M, Pickett CK, Weil JV. Increased carotid body hypoxic sensitivity during acclimatization to hypobaric hypoxia. J Appl Physiol 1987; 63: 2403-2410.

225 Roeggla G, Roeggla M, Wagner A, Laggner AN. Poor ventilatory response to mild hypoxia may inhibit acclimatization at moderate altitude in elderly patients after carotid surgery. Br J Sports Med 1995; 29: 110-112.

226 Wade JG, Larson CP Jr, Hickey RF, Ehrenfeld WK, Severinghaus JW. Effect of carotid endarterectomy on carotid chemoreceptor and baroreceptor function in man. N Engl J Med 1970; 282: 823-829.

227 Lugliani R, Whipp BJ, Seard C, Wasserman K. Effect of bilateral carotid-body resection on ventilatory control at rest and during exercise in man. N Engl J Med 1971; 285: 1105-1111.

228 Honda Y, Watanabe S, Hashizume I, et al. Hypoxic chemosensitivity in asthmatic patients two decades after carotid body resection. J Appl Physiol 1979; 46: 632-638.

229 Hackett PH, Roach RC, Schoene RB, Harrison GL, Mills WJ Jr. Abnormal control of ventilation in high-altitude pulmonary edema. J Appl Physiol 1988; 64: 1268-1272.

230 King $A B$, Robinson SM. Ventilation response to hypoxia and acute mountain sickness. Aerosp Med 1972; 43: 419-421.

231 Moore LG, Harrison GL, McCullough RE, et al. Low acute hypoxic ventilatory response and hypoxic depression in acute altitude sickness. J Appl Physiol 1986; 60: 1407-1412.

232 Chang $\mathrm{KC}$, Morrill CG, Chai H. Impaired response to hypoxia after bilateral carotid body resection for treatment of bronchial asthma. Chest 1978; 73: 667-669.

233 Basnyat B, Litch J. Another patient with neck irradiation and increased susceptibility to acute mountain sickness. Wilderness Environ Med 1977; 8: 176.

234 Rathat C, Richalet JP, Larmignat P, Henry JP. Neck irradiation by cobalt therapy and susceptibility to acute mountain sickness. J Wilderness Med 1993; 4: 231-232.

235 Vanmaele RG, De Backer WA, Willemen MJ, et al. Hypoxic ventilatory response and carotid endarterectomy. Eur J Vasc Surg 1992; 6: 241-244.

236 Kryger M, McCullough R, Doekel R, Collins D, Weil JV, Grover RF. Excessive polycythemia of high altitude: role of ventilatory drive and lung disease. Am Rev Respir Dis 1978; 118: 659-666.

237 Sivak ED, Shefner JM, Sexton J. Neuromuscular disease and hypoventilation. Curr Opin Pulm Med 1999; 5: 355-362.

238 Serebrovskaya T, Karaban I, Mankovskaya I, Bernardi L, Passino C, Appenzeller O. Hypoxic ventilatory responses and gas exchange in patients with Parkinson's disease. Respiration 1998; 65: 28-33.
239 Carroll JE, Zwillich CW, Weil JV. Ventilatory response in myotonic dystrophy. Neurology 1977; 27: 1125-1128.

240 Khan Y, Heckmatt JZ. Obstructive apnoeas in Duchenne muscular dystrophy. Thorax 1994; 49: 157-161.

241 Smith PE, Calverley PM, Edwards RH. Hypoxemia during sleep in Duchenne muscular dystrophy. Am Rev Respir Dis 1988; 137: 884-888.

242 Finnimore AJ, Jackson RV, Morton A, Lynch E. Sleep hypoxia in myotonic dystrophy and its correlation with awake respiratory function. Thorax 1994; 49: 66-70.

243 Mezon BL, West P, Israels J, Kryger M. Sleep breathing abnormalities in kyphoscoliosis. Am Rev Respir Dis 1980; 122: 617-621.

244 Bergofsky EH. Cor pulmonale in the syndrome of alveolar hypoventilation. Prog Cardiovasc Dis 1967; 9: 414-437.

245 Bergofsky EH. Respiratory failure in disorders of the thoracic cage. Am Rev Respir Dis 1979; 119: 643-669.

246 Henry I, Iung B, Piechaud JY, Saidi F, Mayaud C, Boissonnas A. Cardiac cause of hypoxemia in a kyphoscoliotic patient. Eur Respir J 1999; 14: 1433-1434.

247 Benditt JO. Management of pulmonary complications in neuromuscular disease. Phys Med Rehabil Clin N Am 1998; 9: 167-185.

248 Benditt JO, Boitano L. Respiratory support of individuals with Duchenne muscular dystrophy: toward a standard of care. Phys Med Rehabil Clin N Am 2005; 16: 1125-1139.

249 Kumar N, Folger WN, Bolton CF. Dyspnea as the predominant manifestation of bilateral phrenic neuropathy. Mayo Clin Proc 2004; 79: 1563-1565.

250 Sandham JD, Shaw DT, Guenter CA. Acute supine respiratory failure due to bilateral diaphragmatic paralysis. Chest 1977; 72: 96-98.

251 Christensen CC, Ryg MS, Refvem OK, Skjonsberg OH. Effect of hypobaric hypoxia on blood gases in patients with restrictive lung disease. Eur Respir J 2002; 20: 300-305.

252 Lovelace WR, Hinshaw HC. Dangers of aerial transportation to persons with pneumothorax; roentgenographic demonstration of the effect of decreased barometric (high altitude) and of increased barometric pressure. JAMA 1942; 118: 1275-1278.

253 Haid MM, Paladini P, Maccherini M, Di Bisceglie M, Biagi G, Gotti G. Air transport and the fate of pneumothorax in pleural adhesions. Thorax 1992; 47: 833-834.

254 Coudon WL, Block AJ. Acute respiratory failure precipitated by a carbonic anhydrase inhibitor. Chest 1976; 69: 112-113. 